\title{
Targeting of the Hair Cell Proteins Cadherin 23, Harmonin, Myosin XVa, Espin, and Prestin in an Epithelial Cell Model
}

\author{
Lili Zheng, ${ }^{1}$ Jing Zheng, ${ }^{2,4}$ Donna S. Whitlon, ${ }^{2,4}$ Jaime García-Añoveros, ${ }^{3,4}$ and James R. Bartles ${ }^{1,4}$ \\ Departments of ${ }^{1}$ Cell and Molecular Biology, ${ }^{2}$ Otolaryngology, and ${ }^{3}$ Anesthesiology, Neurology, and Physiology and ${ }^{4} \mathrm{Hugh}$ Knowles Center for Clinical \\ and Basic Science in Hearing and Its Disorders, Northwestern University Feinberg School of Medicine, Chicago, Illinois 60611
}

We have developed an advantageous epithelial cell transfection model for examining the targeting, interactions, and mutations of hair cell proteins. When expressed in LLC-PK1-CL4 epithelial cells (CL4 cells), the outer hair cell protein prestin showed faithful domainspecific targeting to the basolateral plasma membrane. We examined the consequences of mutations affecting prestin activity and assigned a targeting role to the cytoplasmic tail. The stereociliary link protein cadherin $23(\mathrm{Cdh} 23)$ was targeted to the plasma membrane of CL4 cell microvilli, the topological equivalent of stereocilia. In cells coexpressing the Cdh 23 cytoplasmic binding protein harmonin, a large fraction of harmonin became colocalized with $\mathrm{Cdh} 23$ in microvilli. Using this assay and in vitro protein binding assays, we formulated an alternative model for Cdh23-harmonin binding, in which the primary interaction is between the harmonin $\mathrm{N}$-domain and a 35-residue internal peptide in the $\mathrm{Cdh} 23$ cytoplasmic tail. Contrary to a previous model, we found no role for the Cdh23 C-terminal PDZ (PSD-95/Dlg/Z0-1)-binding motif and observed that Cdh23 bound similar levels of harmonin with or without the exon 68 peptide. We also examined two proteins involved in stereocilium elongation. The stereociliary actin-bundling protein espin was targeted to CL4 cell microvilli and caused microvillar elongation, whereas espin with the c.2469delGTCA or c.1988delAGAG human deafness mutation showed defects in microvillar targeting and elongation. The unconventional myosin motor myosin XVa accumulated at the tips of espin-elongated microvilli, by analogy to its location in stereocilia, whereas myosin XVa with the c.4351G $>$ A or c.4669A $>$ G human deafness mutation did not, revealing functional deficits in motor activity.

\section{Introduction}

The sensory hair cells responsible for hearing and vestibular function exhibit a high degree of morphological and biochemical specialization to support mechanoelectrical signal transduction (Vollrath et al., 2007). Studying hair cells, however, is a challenge because they are notoriously difficult to access, isolate, and transfect. Moreover, it is exceedingly rare to get a chance to examine the inner ear tissues and hair cells of humans with mutations associated with deafness or vestibular dysfunction. Thus, it would be desirable to have a simple transfection model with which to examine the targeting and interactions of physiologically important hair cell proteins and the effects of their mutations. With rare exceptions (Soni et al., 2005; Grati et al., 2006; Yengo et al., 2008; Peng et al., 2009), investigators have used standard host cell lines, such as HEK293, COS, HeLa, or CHO cells, for such heterologous expression experiments (Boëda et al., 2002; Siemens et al., 2002; Navaratnam et al., 2005; Grillet et al., 2009; Pan et al., 2009). Because hair cells are epithelial cells, we reasoned that there may

\footnotetext{
Received Feb. 16, 2010; revised April 2, 2010; accepted April 5, 2010.

This work was supported by National Institutes of Health Grants DC006412 (J.Z.), DC00653 (D.S.W.), NS044363 (J.G.-A.), and DC004314 (J.R.B.). We thank Dr. Mark S. Mooseker for the CL4 cells, Dr. Thomas B. Friedman for the GFP-myosin XVa construct, Dr. Jon W. Lomasney for the GFP-PH construct, Dr. Vladimir Gelfand for the GFP antibody, and Dr. Sarah E. Rice for myosin discussions.

Correspondence should be addressed to Dr. James R. Bartles, Department of Cell and Molecular Biology, Northwestern University Feinberg School of Medicine, 303 East Chicago Avenue, Chicago, IL 60611. E-mail: j-bartles@northwestern.edu.

DOI:10.1523/JNEUROSCI.0852-10.2010

Copyright $\odot 2010$ the authors $\quad 0270-6474 / 10 / 307187-15 \$ 15.00 / 0$
}

be significant benefit in expressing hair cell proteins in bona fide epithelial cells, which display a characteristic apical-basolateral asymmetry and other features, such as microvilli, which are believed to be related to hair cell stereocilia. Here, we describe in detail an advantageous transfection model for heterologous expression of hair cell proteins that makes use of the LLC-PK1-CL4 epithelial line derived from porcine kidney (Amsler and Cook, 1985; Tyska and Mooseker, 2002). We have used these cells previously to examine the espin actin-bundling proteins (Loomis et al., 2003; Sekerková et al., 2004; Donaudy et al., 2006) and the TRP channel TRPML3 (Nagata et al., 2008). Our new findings demonstrate that this type of approach can be generalized to examine the targeting, interactions, and activities of a wide variety of hair cell proteins. More importantly, this study reveals a great deal of new information about the hair cell proteins cadherin 23, harmonin, myosin XVa, espin, and prestin, which are crucial for hair cell structure and function.

\section{Materials and Methods}

Cell culture and transfection. LLC-PK1-CL4 cells (CL4 cells) are a clone of LLC-PK1 cells (Amsler and Cook, 1985). They were kindly provided by Dr. Mark S. Mooseker (Department of Molecular, Cellular, and Developmental Biology, Yale University, New Haven, CT) (Tyska and Mooseker, 2002). The LLC-PK1 parental cell line and HEK293 cells were from the American Type Culture Collection. Culture media, serum, and reagents were from Invitrogen. CL4 cells and LLC-PK1 cells were cultured at $37^{\circ} \mathrm{C}$ in Invitrogen Minimum Essential Medium Alpha Medium with L-glutamine and without ribonucleotides and deoxyribonucleotides (Alpha Medium) (catalog number 12561-056) containing 10\% (v/v) In- 
vitrogen fetal bovine serum (catalog number 26140-079), $100 \mathrm{U} / \mathrm{ml}$ penicillin $\mathrm{G}$ (sodium salt), and $100 \mu \mathrm{g} / \mathrm{ml}$ streptomycin sulfate. For routine maintenance, the cells were grown in Falcon $100 \mathrm{~mm}$ polystyrene tissue culture dishes (BD Biosciences) until the islands of cells covered $50-70 \%$ of the dish surface, changing medium every $2 \mathrm{~d}$. The cells were passed by trypsinization for $4-5 \mathrm{~min}$ at $37^{\circ} \mathrm{C}$ with $0.05 \%$ Invitrogen trypsin/EDTA (catalog number 25300-054), followed by a 5- to 10-fold dilution into fresh culture medium. To ensure complete cell removal, monolayers were quickly rinsed with the trypsin/EDTA solution one to two times before beginning the trypsinization step. The cells used in experiments were typically passed up to $\sim 25$ times. For storage, cells were frozen in a 9:1 (v/v) mixture of culture medium and dimethylsulfoxide in a liquid nitrogen freezer. As a prelude to transfection, freshly trypsinized and diluted cells were passed into $35 \mathrm{~mm}$ polystyrene tissue culture dishes containing a sterilized, uncoated $22 \times 22 \mathrm{~mm}$ number 1 coverslip. Cells were allowed to grow and differentiate until islands covered $70-80 \%$ of the coverslip surface, which typically required $3-5 \mathrm{~d}$. The medium was changed every $2 \mathrm{~d}$. Cells were transfected with Lipofectamine Reagent (Invitrogen) according to the instructions of the manufacturer. For one $35 \mathrm{~mm}$ dish, this involved preincubating a mixture of $0.15 \mathrm{ml}$ of Alpha Medium containing $\sim 2 \mu \mathrm{g}$ of total plasmid and $0.15 \mathrm{ml}$ of Alpha Medium containing $6 \mu \mathrm{l}$ of Lipofectamine for $30 \mathrm{~min}$ before diluting with $1.5 \mathrm{ml}$ of Alpha Medium. After rinsing cells three times with Alpha Medium, the diluted plasmid-Lipofectamine mixture was applied, and the cells were returned to the incubator for 3-4 h. The cells were then rinsed twice with Alpha Medium before adding complete medium. Cells were examined 18-24 h later. HEK293 cells were cultured and transfected similarly, but Invitrogen DMEM with glutamine and high glucose (catalog number 11965-092) was substituted for Alpha Medium.

Fixation, labeling, and imaging. The baseline processing for the examination of fixed cells involved the following: coverslips were quickly rinsed twice with PBS and incubated for 10 min with $2 \%(\mathrm{w} / \mathrm{v})$ formaldehyde (freshly prepared from paraformaldehyde) in PBS, $5 \mathrm{~min}$ in $0.25 \%(\mathrm{w} / \mathrm{v})$ ammonium chloride in PBS containing $0.01 \%(\mathrm{w} / \mathrm{v})$ saponin (PBS/saponin), $30 \mathrm{~s}$ in $4^{\circ} \mathrm{C} 0.1 \%$ (v/v) Triton X-100 in PBS, 5 min in $0.25 \%(\mathrm{w} / \mathrm{v})$ ammonium chloride in PBS/saponin, $5 \mathrm{~min}$ in $0.4 \%(\mathrm{w} / \mathrm{v})$ bovine serum albumin in PBS/saponin (BSA/PBS/saponin), two times for $5 \mathrm{~min}$ in PBS/saponin, and $5 \mathrm{~min}$ in PBS. When labeling for filamentous actin (F-actin), a 15 min incubation at $37^{\circ} \mathrm{C}$ with Texas Red-X phalloidin (Invitrogen) in BSA/PBS/saponin was inserted after the 5 min incubation in BSA/PBS/saponin. When labeling with epitope tag antibodies, a $25 \mathrm{~min}$ incubation at $37^{\circ} \mathrm{C}$ with commercial anti-tag mouse monoclonal antibody in BSA/PBS/saponin, three 5 min rinses with PBS/ saponin, and a $20 \mathrm{~min}$ incubation at $37^{\circ} \mathrm{C}$ with Texas Red-labeled goat anti-mouse IgG $\mathrm{F}\left(\mathrm{ab}^{\prime}\right)_{2}$ fragment (Jackson ImmunoResearch) in BSA/ $\mathrm{PBS} /$ saponin were inserted after the $5 \mathrm{~min}$ incubation BSA/PBS/saponin. The anti-FLAG (DYKDDDDK) M2 monoclonal antibody was from Sigma. The anti-V5 (GKPIPNPLLGLDST) monoclonal antibody was from Invitrogen. For surface labeling of expressed FLAG-Cdh23 constructs, live-cell staining was performed on ice in a $1^{\circ} \mathrm{C}$ cold room using ice-cold solutions to restrict internalization (McEwen et al., 2007). Coverslips were rinsed two times for $2 \mathrm{~min}$ in Invitrogen Leibovitz's L-15 medium with L-glutamine and without phenol red (catalog number 21083-027) (L-15) and incubated for $4 \mathrm{~min}$ in $2 \%(\mathrm{v} / \mathrm{v})$ goat serum (Jackson ImmunoResearch) in L-15 (GS/L-15), 30 min in anti-FLAG M2 monoclonal antibody (1:500) in GS/L-15, two times for 4 min in L-15, 4 $\mathrm{min}$ in GS/L-15, $30 \mathrm{~min}$ in Texas Red-labeled goat anti-mouse IgG $\mathrm{F}\left(\mathrm{ab}^{\prime}\right)_{2}$ fragment $(1: 160)$ in GS/L-15, three times for $4 \mathrm{~min}$ in $\mathrm{L}-15$, and $12 \mathrm{~min}$ in $2 \%$ formaldehyde in PBS. Specimens were fixed a second time for $10 \mathrm{~min}$ in $2 \%$ formaldehyde in PBS at room temperature and incubated two times for $5 \mathrm{~min}$ in $0.25 \%$ (w/v) ammonium chloride in PBS and $5 \mathrm{~min}$ in PBS before mounting. A FLAG-Cdh23 construct with a severely truncated extracellular domain, which accumulates in intracellular puncta, was used as a negative control in the surface labeling experiments. To reveal this intracellular FLAG-Cdh23 construct, fixed, surface-immunolabeled specimens were permeabilized for $30 \mathrm{~s}$ in $4^{\circ} \mathrm{C}$ $0.1 \%$ (v/v) Triton X-100 in PBS and immunolabeled a second time using anti-FLAG M2 monoclonal antibody and fluorescein-labeled goat antimouse IgG $\mathrm{F}\left(\mathrm{ab}^{\prime}\right)_{2}$ (Jackson ImmunoResearch) following the protocol described above for fixed cells. Specimens were mounted in 5\% (w/v) $n$-propylgallate in glycerol/PBS at 9:1 (v/v) and examined using a Carl Zeiss LSM 510 Meta confocal microscope and a $100 \times, 1.4$ numerical aperture oil-immersion objective. Orthogonal $(x, z$ or $y, z)$ sections were prepared using the LSM510 software. Major qualitative changes in protein localization observed in response to construct mutagenesis or cotransfection, e.g., from plasma membrane to intracellular puncta, from nucleus/cytoplasm to microvilli, or from microvillar tips to cytoplasm, were observed in $>90 \%$ of cells in at least three independent experiments, each examining 80-200 transfected cells. For each quantitative comparison, cells were transfected with the designated constructs, further processed, and imaged at the same time under identical conditions. To compare levels of FLAG-Cdh23 expression with or without exon $68, z$-stacks of images of anti-FLAG-immunolabeled transfected cells $(n=22-25)$ selected at random and collected at the same gain were compressed, and the fluorescence intensity per unit of section area was measured using NIH ImageJ (Wayne Rasband, National Institutes of Health, Bethesda, MD; http://rsb.info.nih.gov/ij/) and corrected for background fluorescence observed in neighboring untransfected cells. The same approach applied to compressed $z$-stacks encompassing microvilli was used to compare the levels of live-cell anti-FLAG immunolabeling at $0-1^{\circ} \mathrm{C}$ for cells transfected with the FLAG-Cdh23 and FLAG-Cdh23 $\mathrm{C} 143$ constructs. The ratio of green fluorescent protein (GFP)-harmonin construct fluorescence to Texas Red-immunolabeled FLAG-Cdh23 construct fluorescence in the microvilli of cotransfected cells, which served as proxy for harmonin binding to the cytoplasmic tail of Cdh23, was quantified using MetaMorph 6.3 (Molecular Devices). For each comparison, immunolabeled cotransfected cells showing similar medium-high levels of GFP and Texas Red fluorescence $(n=23-30)$ were visually selected for analysis and imaged at fixed gain. The MetaMorph inclusive threshold function was used to demarcate microvilli in confocal $z$-stacks and permit measurements of GFP and Texas Red fluorescence intensity per unit of microvillar volume. Data are reported as mean \pm SD in arbitrary units with the control normalized to 1.0. Two sample means were compared by unpaired, two-tailed $t$ test with Welch correction using InStat 3 (GraphPad Software). Representative images are shown in the figures. Average microvillar length in individual transfected cells expressing wild-type espin was determined from confocal images using the LSM510 software as described previously (Loomis et al., 2003) and reported in the figure legend as mean $\pm \mathrm{SD}(n=15$ microvilli). Phase-contrast images of CL4 islands were obtained using a Carl Zeiss Axioplan 2 Imaging microscope equipped with an Axiocam digital camera and a $63 \times, 1.4$ numerical aperture oil-immersion objective. Images were saved in TIF format, and composites were assembled using Photoshop 7.0 (Adobe Systems).

Plasmid constructs and mutagenesis. The prestin-GFP construct contained gerbil prestin (GenBank accession number AF230376) cDNA inserted into the EcoRI site of the pEGFP-N2 vector (Clontech). In the prestin-V5 construct, the cDNA was inserted into the EcoRI site of the pcDNA6/V5-His A vector (Invitrogen). The pendrin-V5 construct contained human pendrin (GenBank accession number NM_000441) cDNA inserted into the NheI and BamHI sites of the pcDNA6/V5-His C vector (Invitrogen). There are two models of prestin topology, one with 10 (Navaratnam et al., 2005) and one with 12 (Deák et al., 2005) membrane-spanning domains. Both models have the same C-terminal membrane-spanning segment and cytoplasmic tail. We have adopted the 10-membrane-spanning segment model (Fig. 1A). The chimeric pendrin-prestin-V5 construct in the pcDNA6/V5-His vector seamlessly joined pendrin L506 to prestin L497 in the four-residue LLTV sequence, which they share at the site in which their C-terminal membranespanning segment joins the cytoplasmic tail (shown for prestin in Fig. $1 A)$. This chimeric construct was assembled using PCR to introduce a $\mathrm{KpnI}$ site at the locations in the pendrin and prestin cDNA fragments that were to be joined and then removing the extra nucleotides by cutting the ligated product with KpnI and trimming the $3^{\prime}$-overhangs with T4 DNA polymerase (New England Biolabs). The Cdh23 construct was prepared from a cDNA (GenBank accession number AK039126) corresponding to mouse Cdh23_v4 without exon 68 (Lagziel et al., 2009). Cdh23_v4 transcripts, in which exon 44 is spliced directly to exon 48 , are of moderate abundance in inner ear from birth to adulthood (Lagziel et al., 2009). The 


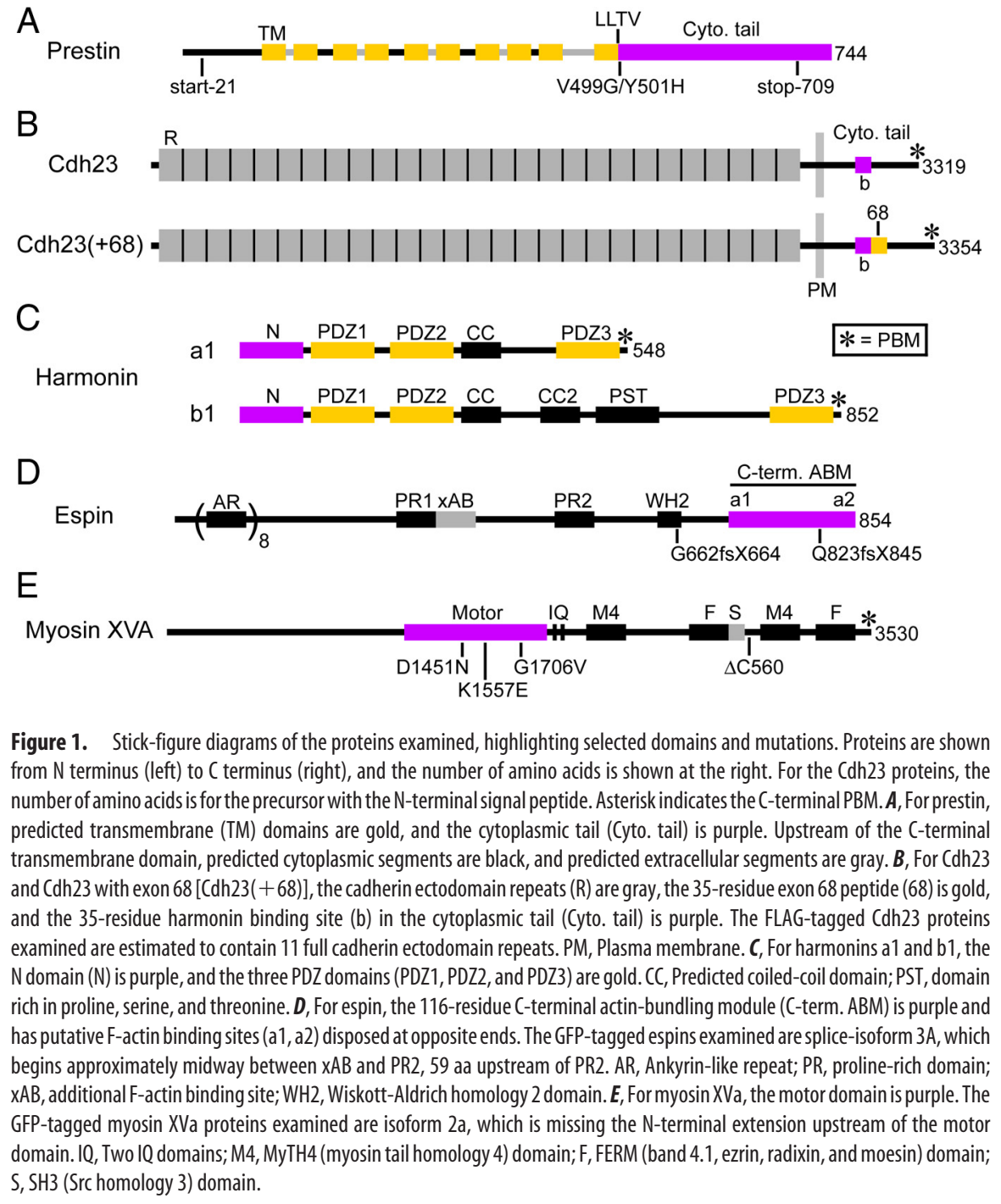

FLAG-Cdh23 construct used in our experiments was the 3' -fragment of this cDNA that began at the SalI site corresponding to nucleotide 4129 of GenBank accession number NM_023370. It was joined in-frame to the SalI site in the multiple cloning site of the pFLAG-CMV-1 vector (Sigma), which encodes a preprotrypsin signal peptide upstream of the FLAG sequence. Because of the truncation of the $5^{\prime}$-end of the cDNA and the absence of exons 45-47, we estimate that this Cdh23 construct contains 11 full cadherin ectodomain repeats (Di Palma et al., 2001b). The FLAG-Cdh23 plus exon 68 construct encodes a protein with an additional 35-residue internal peptide in the cytoplasmic tail (Di Palma et al., 2001b; Siemens et al., 2002) (Fig. 1B). It was prepared using a cDNA fragment that included exon 68 , which was obtained by reverse transcription (RT)-PCR from isolated mouse cochlear sensory epithelium (Sekerková et al., 2004; Whitlon et al., 2006). A FLAG-Cdh23 with a severely truncated extracellular tail (only $\sim 26$ extracellular Cdh23 amino acids remaining) was used as an intracellular control in live-cell staining at $0-1^{\circ} \mathrm{C}$. It was prepared by joining the $\mathrm{XmnI}$ site corresponding to nucleotide 9122 in GenBank accession number NM_023370 in-frame to the blunted EcoRI site of pFLAG-CMV-1. For bacterial expression, glutathione $S$-transferase (GST) Cdh23 cytoplasmic tail constructs starting from nucleotide 9283 of GenBank accession number NM_023370 were prepared from the corresponding pFLAG-CMV-1 constructs by PCR and inserted into the BamHI and EcoRI sites of the pGEX-4T-2 vector (GE Healthcare). The GFP-tagged pleckstrin homology domain of human phospholipase C $\delta 1$ (GFP-PH) (Stauffer et al., 1998) was kindly provided by Dr. Jon W. Lomasney (Department of Pathology, Northwestern University Feinberg School of Medicine, Chicago, IL). The
cDNA for harmonin al (GenBank NM_153677), which was obtained by RT-PCR from mouse kidney, was inserted into the KpnI and BamHI sites of the pEGFP-C1 vector (Clontech) for transfection or the StuI site of the ProEXHTa vector (Invitrogen) for bacterial expression. In the corresponding harmonin al protein (GenBank accession number NP_076138) (Fig. 1C), the N-domain + PDZ1 construct ended at S190, and the $\Delta \mathrm{N}$-domain construct and the PDZ2 + PDZ3 construct began at K84 and S174, respectively. The harmonin b1 (Verpy et al., 2000) construct, which encodes an additional predicted coiled-coil domain and proline-serine-threonine domain between the PDZ2 and PDZ3 domains (Fig. $1 C$ ), was prepared using cDNA fragments obtained by RT-PCR from isolated mouse cochlear sensory epithelium (Sekerková et al., 2004; Whitlon et al., 2006) and was inserted in the KpnI and BamHI sites of the pEGFP-C1 vector. Human espin 3A cDNA (Sekerková et al., 2004; Donaudy et al., 2006; Purdy et al., 2007), which corresponds to nucleotides 17772733 of GenBank accession number NM_031475 and encodes an isoform that begins 59 aa upstream of proline-rich domain 2 (Fig. 1D), was obtained by RT-PCR from human testis total RNA (Clontech) and inserted into the SmaI site of the PEGFP-C2 vector. The untagged espin construct was rat espin $2 \mathrm{~B}$ cDNA (formerly rat Purkinje cell espin 1; GenBank accession number AF540946) inserted into the EcoRV site of the pcDNA3 vector (Invitrogen). The GFP-myosin XVa construct, which contained the cDNA for mouse myosin $\mathrm{XVa}$ isoform 2a (GenBank accession number AY331133) inserted into the EcoRI and SalI sites of the pEGFP-C2 vector (Belyantseva et al., 2003, 2005), was kindly provided by Dr. Thomas B. Friedman (Laboratory of Molecular Genetics, National Institute on Deafness and Other Communication Disorders, Bethesda, MD). This endogenously expressed inner ear isoform is missing exon 2, which encodes the large $\mathrm{N}$-terminal extension upstream of the motor domain (Fig. $1 E$ ) and thus corresponds to the predominant form in inner ear (Belyantseva et al., 2003). Motor domain mutations were introduced into the AatII fragment (nucleotides 501-1659 of GenBank accession number AY331133) while the cDNA was temporarily inserted into a pEGFP-C1 vector modified to remove all AatII sites. The $\Delta \mathrm{C} 560$ construct (Fig. $1 E$ ) was produced by SacII cleavage of the cDNA. RNA isolation and RT-PCR were performed using Trizol, enzymes, and reagents from Invitrogen. Mutagenesis was performed using a combination of PCR and restriction enzyme digestion. All cDNA constructs were checked by DNA sequence analysis.

In vitro binding assays. Mouse harmonin al was expressed with a short $\mathrm{N}$-terminal 6xHis tag in Escherichia coli BL21 Star (DE3) cells (Invitrogen) using the ProEXHTa vector. The protein was affinity purified under nondenaturing conditions from soluble bacterial extracts containing 1 mM phenylmethylsulfonyl fluoride on Ni-NTA agarose beads (Qiagen) (Chen et al., 1999), dialyzed against binding assay buffer (100 mM KCl, 20 mм imidazole- $\mathrm{HCl}, 1 \mathrm{~mm}$ dithiothreitol, and $3 \mathrm{~mm} \mathrm{NaN}_{3}, \mathrm{pH}$ 7.4), and clarified by ultracentrifugation, all at $4^{\circ} \mathrm{C}$. Mouse $\mathrm{Cdh} 23$ cytoplasmic tail constructs were expressed with an N-terminal GST tag using the pGEX$4 \mathrm{~T}-2$ vector. The GST-Cdh23 tail proteins were bound from soluble bacterial PBS extracts containing $1 \mathrm{~mm}$ phenylmethylsulfonyl fluoride in approximately equal molar levels to glutathione-Sepharose $4 \mathrm{~B}$ beads (GE Healthcare) at $4^{\circ} \mathrm{C}$, washing five times with binding assay buffer. The purified harmonin al protein was incubated with the washed glutathio- 
ne-Sepharose 4B beads preloaded with GSTCdh23 tail construct or GST alone in binding assay buffer for $1 \mathrm{~h}$ at $22^{\circ} \mathrm{C}$ in $1.5 \mathrm{ml}$ microcentrifuge tubes on a rotator. After washing five times with binding assay buffer in the microfuge at $13,000 \times g$ for $30 \mathrm{~s}$ at $4^{\circ} \mathrm{C}$, the bound proteins were released by heating at $100^{\circ} \mathrm{C}$ for 3 min in SDS gel sample buffer containing 3 $\mathrm{mg} / \mathrm{ml}$ dithiothreitol and resolved in $9 \%(\mathrm{w} / \mathrm{v})$ SDS-polyacrylamide gels. Gels were stained with Coomassie blue. The intensities of the harmonin a1 bands were measured by scanning gels using the Image Station 440CF and Molecular Imaging software from Eastman Kodak and corrected for the background present in GST controls. The levels of harmonin bound were graphed as a percentage of the harmonin al added to the binding assay. Sample means obtained from three independent experiments were compared with one another by one-way ANOVA using the Tukey-Kramer multiple comparisons test (InStat 3). Apparent molecular mass was estimated using the BenchMark Prestained Protein Ladder (Invitrogen).

Western blotting. Dishes of transfected CL4 cells were quickly rinsed twice in PBS, $0.6 \mathrm{ml}$ of $100^{\circ} \mathrm{C}$ SDS gel sample buffer containing 3 $\mathrm{mg} / \mathrm{ml}$ dithiothreitol was added, and the cells were dissolved by pipetting the hot gel sample buffer up and down onto the surface seven to eight times. The resulting solution was transferred to a $1.5 \mathrm{ml}$ microcentrifuge tube, heated for $3 \mathrm{~min}$ at $100^{\circ} \mathrm{C}$, with brief vortex mixing at $1 \mathrm{~min}$ intervals, resolved in 6\% (w/v) SDSpolyacrylamide gels, and electrophoretically transferred to nitrocellulose membrane $(7-8 \mathrm{~h}$, $400 \mathrm{~mA}$ ) in the presence of $0.1 \%(\mathrm{w} / \mathrm{v})$ SDS and $20 \%(\mathrm{v} / \mathrm{v})$ methanol. Expressed GFP-labeled proteins were detected using a rabbit polyclonal GFP antibody, which was kindly provided by Dr. Vladimir Gelfand (Department of Cell and Molecular Biology, Northwestern University Feinberg School of Medicine, Chicago, IL), using the ECL method (GE Healthcare). The intensities of wild-type and mutated GFP-myosin XVa protein bands from three independent cotransfection experiments with untagged espin construct were measured by scanning films using the Eastman Kodak Image Station 440CF and Molecular Imaging software and corrected for background in samples prepared from control cells transfected with untagged espin construct alone. Mean band intensities obtained for the mutated GFP-myosin XVa constructs were compared with the wild-type control by one-way ANOVA using the Dunnett's multiple comparisons test (InStat 3).

\section{Results}

Properties of CL4 cells

When plated on glass coverslips, CL4 cells grow in islands to form epithelial monolayers (Fig. 2A). Labeling with fluorescent phalloidin reveals an intensely labeled F-actin-rich junctional belt, which surrounds their lateral-apical margin (Fig. $2 B$ ), and a weakly labeled collection of relatively short $(\sim 1 \mu \mathrm{m})$, uniform brush border microvilli, which emanate from their apical surface (Fig. 2 B, C). CL4 cells offer a number of advantages. They require no special substrate or medium ingredients to undergo epithelial
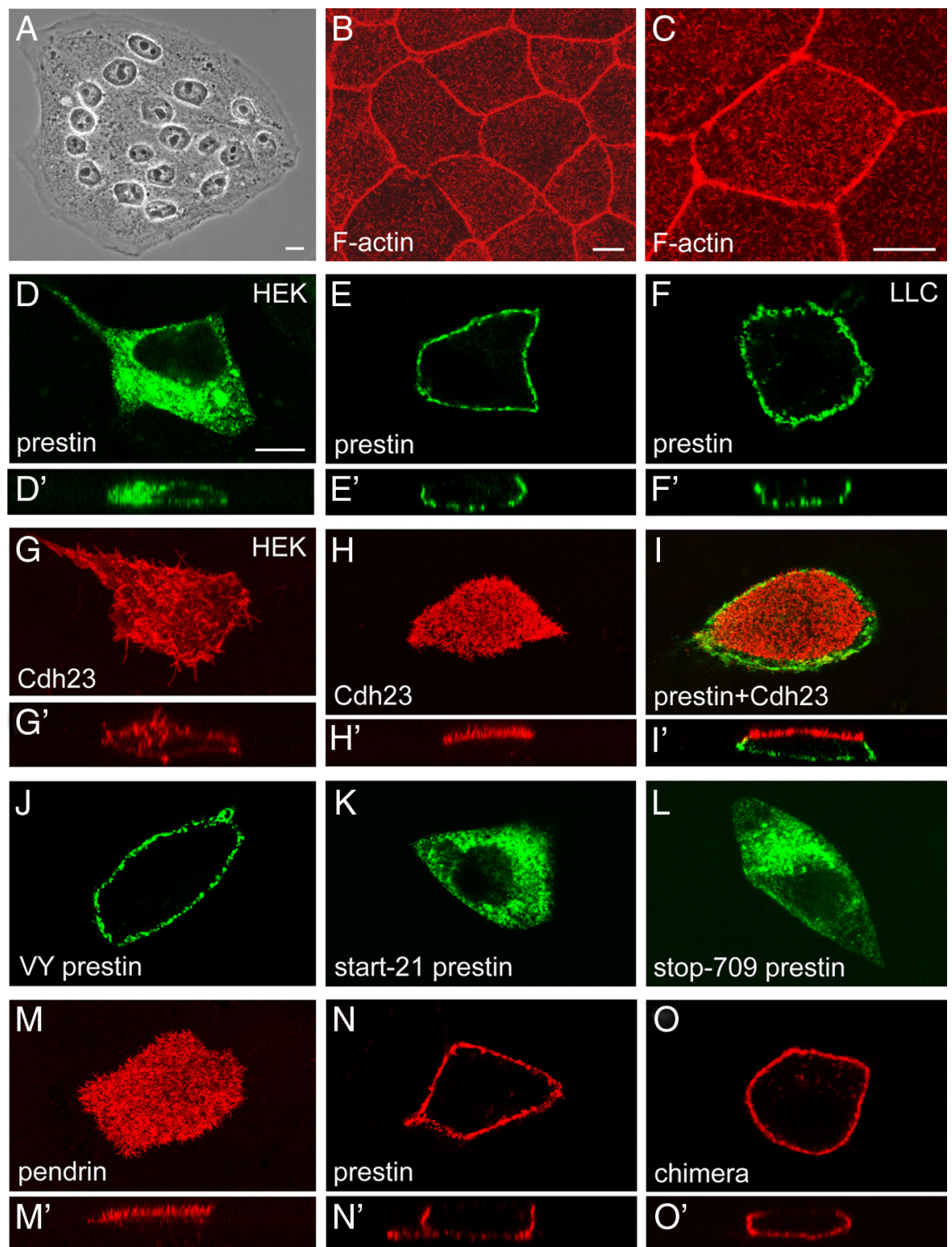

Figure 2. Domain-specific plasma membrane targeting of prestin and Cdh23. Cells are CL4 unless indicated otherwise in top right corner. $\boldsymbol{A}-\boldsymbol{C}, \mathrm{CL} 4$ cell grow in islands $(\boldsymbol{A})$ and undergo epithelial differentiation, as revealed in part by Texas Red-X phalloidin, which labels $F$-actin in the junctional belt and short brush border microvilli ( $\boldsymbol{B}, \boldsymbol{C})$. D-F', Prestin-GFP (prestin) accumulates in cytoplasmic puncta in HEK293 cells (HEK) (D, $\left.\boldsymbol{D}^{\prime}\right)$ but in the basolateral plasma membrane of CL4 cells $\left(\boldsymbol{E}, \boldsymbol{E}^{\prime}\right)$ and LLC-PK1 cells (LLC) $\left(\boldsymbol{F}, \boldsymbol{F}^{\prime}\right) . \mathbf{G}-\boldsymbol{H}^{\prime}$, FLAG-Cdh23 (Cdh23) accumulates in irregular, filopodium-like surface projections of HEK293 cells (HEK) $\left(\boldsymbol{G}, \boldsymbol{G}^{\prime}\right)$ but in the microvillar (apical) plasma membrane of CL4 cells $\left(\boldsymbol{H}, \boldsymbol{H}^{\prime}\right.$ ) (also see Fig. 3). $\boldsymbol{I}, \boldsymbol{I}^{\prime}$, A cotransfected CL4 cell accumulates prestin-GFP (prestin; green) and FLAG-Cdh23 (Cdh23; red) in the basolateral and microvillar (apical) plasma membrane, respectively. J-L, Prestin-GFP with the V499G/Y501H (VY) double mutation accumulates in the basolateral plasma membrane $(\boldsymbol{J})$, but prestin-GFP with the start-21 $(\boldsymbol{K})$ or stop-709 $(\boldsymbol{L})$ truncation mutation accumulates in intracellular puncta. $\boldsymbol{M}-\mathbf{O}^{\prime}$, Pendrin-V5 (pendrin) accumulates in the microvillar (apical) plasma membrane $\left(\boldsymbol{M}, \boldsymbol{M}^{\prime}\right)$, prestin-V5 (prestin) accumulates in the basolateral plasma membrane $\left(\boldsymbol{N}, \boldsymbol{N}^{\prime}\right)$, and a pendrin-prestin-V5 chimera (chimera), in which the prestin cytoplasmic tail substitutes for the pendrin cytoplasmic tail, accumulates in the basolateral plasma membrane $\left(\mathbf{0}, \mathbf{O}^{\prime}\right)$. Orthogonal sections: $x_{\boldsymbol{\prime}} \mathrm{Z}$ $\left(\boldsymbol{D}^{\prime}-\boldsymbol{F}^{\prime}, \boldsymbol{H}^{\prime}, \boldsymbol{M}^{\prime}\right) ; y, z\left(\boldsymbol{G}^{\prime}, \boldsymbol{I}^{\prime}, \boldsymbol{N}^{\prime}, \boldsymbol{O}^{\prime}\right)$. Scale bars, $10 \mu \mathrm{m}$ (scale bar in $\boldsymbol{D}$ applies to $\left.\boldsymbol{D}-\boldsymbol{O}^{\prime}\right)$.

differentiation. Instead, this differentiation occurs naturally as the cells reside in islands on glass coverslips, usually over the course of 3-5 d. CL4 cells are relatively short but have a large apical surface area. This makes them especially well-suited for the imaging of apical (microvillar) proteins, which includes heterologously expressed stereociliary proteins, such as espin (Loomis et al., 2003; Sekerková et al., 2004; Donaudy et al., 2006). Finally, CL4 cells are simple to transfect while in epithelial monolayers and can be transfected with multiple constructs simulta- 

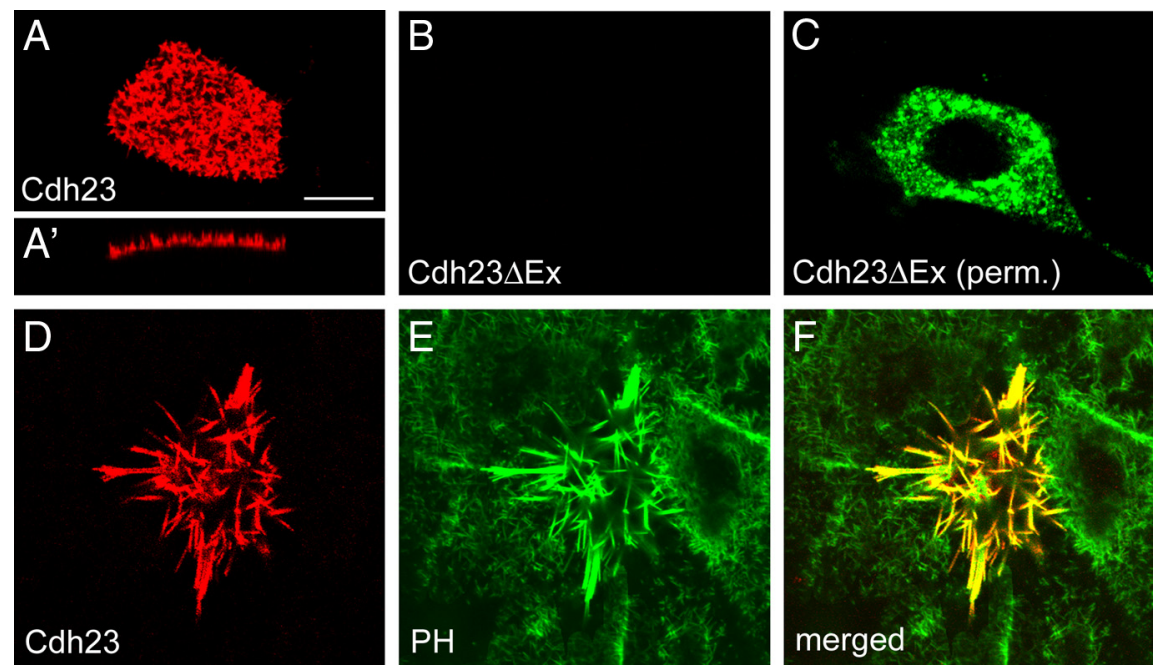

Figure 3. Live-cell surface immunolabeling of microvillar FLAG-Cdh23 at $0-1^{\circ} \mathrm{C}$ and colocalization with the plasma membrane marker GFP-PH. $\boldsymbol{A}, \boldsymbol{A}^{\prime}$, Live-cell labeling of CL4 cell expressing FLAG-Cdh23 with FLAG antibody and Texas Red-labeled secondary antibody followed by fixation, all at $0-1^{\circ} \mathrm{C}$ to restrict internalization, reveals intense microvillar staining. $\boldsymbol{A}^{\prime}, y, z$ orthogonal section. $\boldsymbol{B}, \boldsymbol{C}, \mathrm{CL} 4$ cell expressing FLAG-Cdh23 with a severely truncated extracellular domain (Cdh23 $\Delta \mathrm{Ex})$, which accumulates in intracellular puncta, shows no such live-cell labeling with FLAG antibody and Texas Red-labeled secondary antibody at $0-1^{\circ} \mathrm{C}(\boldsymbol{B})$, but this intracellular FLAG-Cdh23 construct is revealed after a second labeling with FLAG antibody followed by fluorescein-labeled secondary antibody after brief permeabilization (perm.) at $4^{\circ} \mathrm{C}$ with $0.1 \%$ (v/v) Triton X-100 (C). D-F, Live-cell anti-FLAG labeling at $0-1^{\circ} \mathrm{C}$, as in $\boldsymbol{A}$, of a triply transfected $\mathrm{CL} 4$ cell expressing FLAG-Cdh23, untagged espin (to elongate microvilli), and the plasma membrane marker GFP-PH. Note that the surface-immunolabeled FLAG-Cdh23 is present along espin-elongated microvilli $(\boldsymbol{A})$ and colocalizes with GFP-PH (B), as evident in the merged image (C). Scale bar: $\boldsymbol{A}-\boldsymbol{F}, 10 \mu \mathrm{m}$.

neously. Standard lipid-based transfection reagents typically yield $10-30 \%$ transfection efficiency for a single plasmid. This level of transfection allows for the ready observation of hundreds of examples of transfected cells surrounded by untransfected control cells on a single coverslip and is high enough to permit tests of expressed protein integrity on Western blots if desired. CL4 cells are a clone of LLC-PK1 cells and were studied initially for their high-capacity $\mathrm{Na}^{+}$-dependent hexose uptake (Amsler and Cook, 1985). We have observed that CL4 cells form epithelial monolayers more rapidly than LLC-PK1 cells when plated on glass coverslips. A potential drawback is that cells of the LLC-PK1 parental line lack the $\mu 1 \mathrm{~B}$ subunit of adaptor complex AP-1B and, as a result, incorrectly sort certain basolateral plasma membrane proteins that use a tyrosine-based sorting motif to the apical plasma membrane (Fölsch, 2005). Thus, CL4 cells might also have this problem. If this were to become an issue for a given protein, it could potentially be remedied by stable transfection with $\mu 1 \mathrm{~B}$ (Fölsch et al., 1999).

\section{Domain-specific targeting of the hair cell plasma membrane proteins prestin and $\mathrm{Cdh} 23$}

We found that expressing certain hair cell plasma membrane proteins in CL4 cells could greatly increase their efficiency of plasma membrane targeting over that observed in commonly used nonepithelial cell lines. This result was exemplified by the situation for the outer hair cell "motor" protein prestin (J. Zheng et al., 2000), also known as SLC26A5, which is predicted to have 10 membrane-spanning domains (Navaratnam et al., 2005) (Fig. $1 A)$. This member of the SLC26 family of multifunctional anion exchangers (Mount and Romero, 2004) mediates outer hair cell electromotility and cochlear amplification (Dallos et al., 2008) and has been localized to the lateral and, to a lesser extent, the basal plasma membrane domains of outer hair cells (Belyantseva et al., 2000; Zheng et al., 2003; Yu et al., 2006; Jensen-Smith and
Hallworth, 2007). During heterologous expression in HEK293 cells, a nonepithelial cell line commonly used in transfection studies, a majority of prestin-GFP accumulated in perinuclear intracellular puncta, which likely included membranous elements of the secretory and/or endocytic pathways (Fig. 2D, $D^{\prime}$ ). However, during heterologous expression in CL4 cells, a majority of prestin-GFP accumulated in the basolateral plasma membrane (Fig. $\left.2 E, E^{\prime}\right)$, mirroring its endogenous localization in outer hair cells. Only very low levels of prestin-GFP could be observed intracellularly, away from cell margins, and little or no prestin-GFP could be discerned in the apical/microvillar plasma membrane (Fig. $2 E, E^{\prime}$ ). The same basolateral targeting result was obtained for prestin-GFP in cells of the LLC-PK1 parental line (Fig. $2 F, F^{\prime}$ ).

The complementary plasma membrane targeting result was observed for a Cdh23 construct in CL4 cells. Cdh23 is a type I membrane protein and atypical cadherin (Bork et al., 2001; Di Palma et al., 2001a) (Fig. 1B). It has been localized to the stereociliary plasma membrane and implicated in transient lateral and tip links between neighboring hair cell stereocilia (Siemens et al., 2004; Lagziel et al., 2005; Michel et al., 2005). Most recently, Cdh23 has been shown to form the upper part of the tip link and to be associated with the upper tip-link density (Kazmierczak et al., 2007; Grillet et al., 2009). Accordingly, during heterologous expression in CL4 cells, a Cdh23 construct with an N-terminal (extracellular) FLAG tag accumulated in the apical (microvillar) plasma membrane (Fig. $2 \mathrm{H}, \mathrm{H}^{\prime}$ ), the topological equivalent of the stereociliary plasma membrane in hair cells. Little or no FLAGCdh23 was observed intracellularly or in the basolateral plasma membrane. Live-cell labeling with anti-FLAG monoclonal antibody and Texas Red-labeled secondary antibody followed by fixation, all conducted at $0-1^{\circ} \mathrm{C}$ to restrict internalization, confirmed that the FLAG-Cdh23 was distributed in the microvillar plasma membrane as expected, with the FLAG epitope exposed to the extracellular medium (Fig. $3 A, A^{\prime}$ ). This live-cell labeling result was obtained for each of the FLAG-Cdh23 constructs used in this study (data not shown), with one crucial exception: to confirm the surface specificity of the live-cell labeling protocol, we also examined a FLAG-Cdh23 construct with a severely truncated extracellular tail, which does not accumulate in the microvillar plasma membrane but in intracellular puncta. Live-cell labeling with anti-FLAG monoclonal antibody and Texas Red-labeled secondary antibody at $0-1^{\circ} \mathrm{C}$ was not detected for this FLAG-Cdh23 construct in microvilli or in the cytoplasm (Fig. 3B). This intracellular FLAG-Cdh23 construct did, however, become clearly evident in cytoplasmic puncta when the fixed cells were briefly permeabilized with ice-cold $0.1 \%$ Triton X-100 and labeled a second time with anti-FLAG monoclonal antibody followed by FITC-labeled secondary antibody (Fig. 3C). Additional confirmation that the FLAG-Cdh23 was in the microvillar plasma membrane came from experiments examining the effects of coexpression with untagged espin actin-bundling protein, which dramatically increases the size of CL4 cell mi- 
crovilli (Loomis et al., 2003) (see more below) and hence the size of the surface-immunolabeled FLAG-Cdh23-containing projections (Fig. 3D), and from colocalization with GFP-PH, a plasma membrane marker containing the pleckstrin homology domain of phospholipase $C \delta 1$, which binds phosphatidylinositol-4,5bisphosphate in the inner leaflet of the plasma membrane (Stauffer et al., 1998) (Fig. 3D-F). When expressed in HEK293 cells, a significant fraction of the FLAG-tagged Cdh23 construct also appeared to reach the plasma membrane, but its distribution about the cell surface and enrichment in irregular, filopodiumlike surface projections (Fig. $2 G, G^{\prime}$ ) made its localization pattern less distinct than in CL4 cells (compare orthogonal sections in Fig. $\left.2 G^{\prime}, H^{\prime}\right)$. In summary, constructs for the hair cell plasma membrane proteins prestin and Cdh23 showed efficient and faithful domain-specific plasma membrane targeting during heterologous expression in CL4 epithelial cells. In fact, when coexpressed in the same transfected CL4 cell, the prestin-GFP and FLAG-Cdh23 constructs were efficiently targeted to the basolateral and apical (microvillar) plasma membrane domains, respectively (Fig. 2I, $I^{\prime}$ ).

The V499G/Y501H double mutation (Fig. 1A) eliminates the nonlinear capacitance and cochlear amplification of prestin (Zheng et al., 2005; Dallos et al., 2008). Prestin with the V499G/ $\mathrm{Y} 501 \mathrm{H}$ double mutation was targeted to the basolateral plasma membrane domain in CL4 cells (Fig. $2 J$ ), recapitulating the proper basolateral plasma membrane targeting noted for this mutated prestin protein in knock-in mice (Dallos et al., 2008). In contrast, truncation mutations removing amino acids 1-20 from the prestin $\mathrm{N}$ terminus (start-21) or amino acids 710-744 from the prestin C terminus (stop-709) (Fig. 1A), both of which eliminated nonlinear capacitance but not surface delivery of prestinyellow fluorescent protein or prestin-GFP constructs in $\mathrm{CHO}$ cells (Navaratnam et al., 2005), greatly increased intracellular accumulation of prestin-GFP in CL4 cells (Fig. $2 \mathrm{~K}, L$ ). This suggested that there may be different requirements to achieve proper surface delivery of prestin constructs in epithelial cells.

To demonstrate that the CL4 cell model can be used to identify domains involved in plasma membrane targeting, we used the well established "transplantation" strategy (Carmosino et al., 2010) to determine whether the prestin C-terminal cytoplasmic tail was sufficient to act as an autonomous sorting signal for targeting to the basolateral plasma membrane. The "transplant recipient" for these experiments was another member of the SLC26 family, pendrin (SLC26A4), an electroneutral $\mathrm{Cl}^{-}$/ $\mathrm{HCO}_{3}^{-} / \mathrm{I}^{-}$exchanger (Shcheynikov et al., 2008) that is $38 \%$ identical in amino acid sequence to prestin and believed to have a related topology (Everett et al., 1997; Mount and Romero, 2004). Although pendrin is not present in hair cells (Royaux et al., 2003), it is associated with sensorineural hearing loss in Pendred's syndrome and with nonsyndromic deafness in DFNB4 (Kopp et al., 2008; Anwar et al., 2009). In the inner ear, pendrin is detected at high levels in cells of the endolymphatic sac and duct and the outer sulcus and is believed to affect hearing through its effect on endolymphatic $\mathrm{HCO}_{3}^{-}$levels or resorption (Royaux et al., 2003). Pendrin is also prevalent in the thyroid and in certain kidney epithelial cells, in which it is concentrated in the apical plasma membrane domain (Royaux et al., 2000; Kim et al., 2002). For these experiments, we used constructs with a V5 peptide epitope tag. When expressed in transfected CL4 cells, pendrin-V5 was efficiently targeted to the apical/microvillar plasma membrane (Fig. $2 M, M^{\prime}$ ), by analogy to its localization in these transporting epithelia. As expected from our results examining prestin-GFP (Fig. $2 E, E^{\prime}$ ), prestin-V5 was efficiently targeted to the basolateral domain (Fig. $2 N, N^{\prime}$ ). However, when the cytoplasmic tail of pendrin was substituted with that of prestin (Fig. $1 A$ ), the resulting pendrin-prestin-V5 chimera was targeted to the basolateral domain (Fig. 2O, $\mathrm{O}^{\prime}$ ). This result suggested that a dominant basolateral sorting motif (Carmosino et al., 2010) was present in the 247-residue cytoplasmic tail of prestin.

\section{Binding between the stereociliary proteins $\mathrm{Cdh} 23$ and harmonin}

To demonstrate that CL4 cells can be used to explore potential binding interactions between stereociliary proteins, we examined interactions between $\mathrm{Cdh} 23$ and the cytoplasmic adaptor protein harmonin (Bitner-Glindzicz et al., 2000; Verpy et al., 2000). Harmonin has been implicated as a central organizer of the Usher "interactome," an interacting network of stereocilium-associated membrane and cytoplasmic proteins, mutations of which can give rise to the different classes of Usher syndrome (El-Amraoui and Petit, 2005; Reiners et al., 2006; Müller, 2008). Harmonin comes in a variety of splice isoforms (Verpy et al., 2000; Boëda et al., 2002). For simplicity, we focused on harmonin a1, which contains an $\sim 90$-residue $\mathrm{N}$-terminal $\mathrm{N}$-domain with a relatively novel five $\alpha$-helix-bundle fold (Pan et al., 2009) and three putative PDZ (PSD-95/Dlg/ZO-1) domains (PDZ1, PDZ2, and PDZ3) (Fig. 1C). The prevailing model suggests that harmonin a1 binds to two different sites on the cytoplasmic tail of Cdh23: a canonical four-residue C-terminal class I PDZ-binding motif (PBM), consisting of the amino acids -ITEL, and an internal peptide upstream in the cytoplasmic tail (Siemens et al., 2002; Müller, 2008; Grillet et al., 2009; Pan et al., 2009).

When expressed in CL4 cells, GFP-harmonin al was distributed diffusely in the cytoplasm and appeared, inexplicably, to be concentrated in the nucleus (Fig. $4 A, A^{\prime}$ ). However, when coexpressed with FLAG-Cdh23 in cotransfected CL4 cells, a large fraction of the GFP-harmonin al became colocalized with the FLAG-Cdh23 construct in CL4 cell microvilli (Fig. $4 B-D^{\prime}$ ). This change in GFP-harmonin a1 localization to CL4 cell microvilli was clearly evident in confocal top (Fig. $4 B$ ) and orthogonal (Fig. $\left.4 B^{\prime}\right)$ views. This colocalization in a discrete, easily recognizable and biologically relevant subcellular compartment of these epithelial cells was suggestive of a binding interaction between the two expressed proteins in vivo. Thus, we used microvillar colocalization to test certain hypotheses about the interaction between Cdh23 and harmonin and then validated our key findings using in vitro binding assays examining the corresponding purified recombinant proteins.

We wondered whether the high level of colocalization between GFP-harmonin al and FLAG-Cdh23 observed in the microvilli of cotransfected CL4 cells (Fig. $4 B-D^{\prime}$ ) might reflect amplification attributable to harmonin-harmonin interactions. The final four amino acids of harmonin a1, -LTFF, fit the canonical four-residue C-terminal class I PBM consensus (Fig. 1C), and one group reported an interaction between this PBM and the PDZ1 domain of harmonin in yeast two-hybrid assays (Siemens et al., 2002). The GFP-harmonin/FLAG-Cdh23 (H/C) ratios in microvilli for the harmonin a1 and harmonin a1 $\Delta C 4$ constructs were indistinguishable $(1.0 \pm 0.2$ and $1.0 \pm 0.2 ; p=0.6)$ (Fig. $4 B-G)$. This result suggested that such harmonin-harmonin interactions were not required for the high level of colocalization observed in CL4 cell microvilli.

To ascertain whether the colocalization of GFP-harmonin a1 and FLAG-Cdh 23 in CL4 cell microvilli might represent binding via suspected binding sites on the two proteins, we examined the effects of including or deleting selected protein domains. In view of the 
harm alone

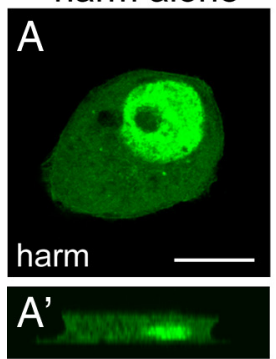

harm construct
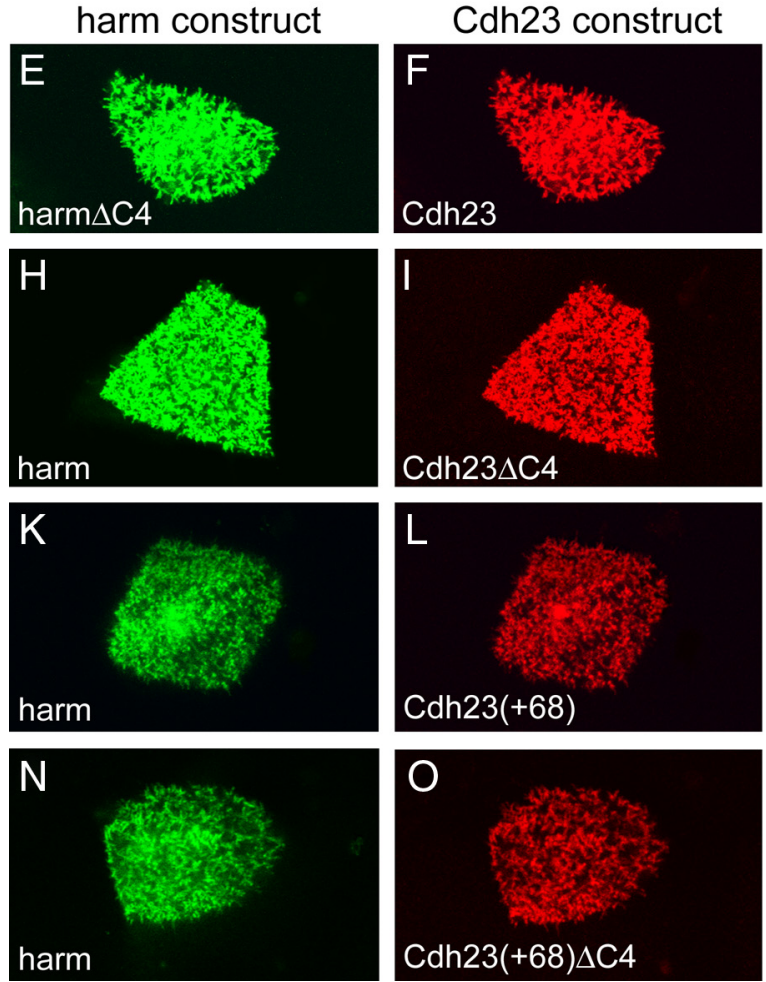

harm + Cdh23
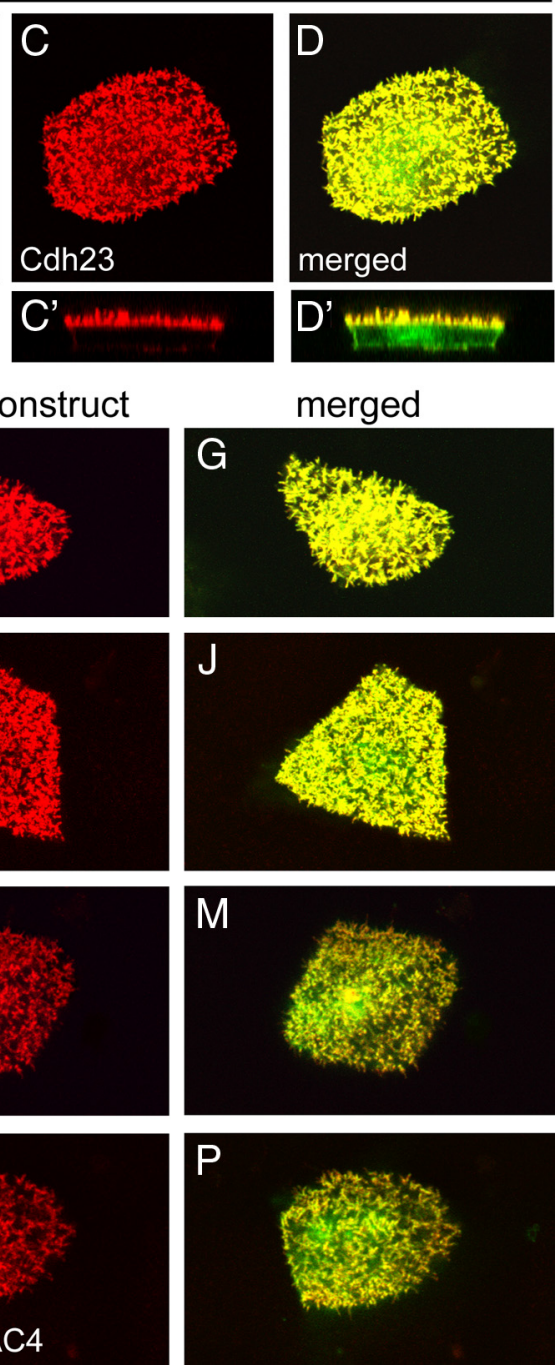

Figure 4. Colocalization of GFP-harmonin a1 with microvillar FLAG-Cdh23. $A, A^{\prime}$, When expressed without FLAG-Cdh23, GFP- harmonin a1 (harm) accumulates in the nucleus and cytoplasm but not in microvilli. $\boldsymbol{B}-\boldsymbol{D}^{\prime}$, When coexpressed with FLAGCdh23 (Cdh23), a large fraction of GFP-harmonin a1 (harm) colocalizes with FLAG-Cdh23 in microvilli, suggestive of binding between the two expressed proteins. $\boldsymbol{E}-\boldsymbol{G}$, Elimination of the four-residue C-terminal PBM from harmonin a1 (harm $\Delta(4)$ does not decrease GFP-harmonin a1 (harm) construct colocalization in microvilli (compare with $\boldsymbol{B}-\boldsymbol{D}$ ). $\boldsymbol{H}$-J, Elimination of the four-residue C-terminal PBM from FLAG-Cdh23 (Cdh23 $\Delta$ C4) does not decrease GFP- harmonin a1 (harm) colocalization in microvilli (compare with $\boldsymbol{B}-\boldsymbol{D}) . \boldsymbol{K}-\boldsymbol{P}$, Although $\mathrm{FLAG}-\mathrm{Cdh} 23$ with the exon 68 peptide $[\mathrm{Cdh} 23(+68)]$ shows approximately threefold lower levels of accumulation than FLAG-Cdh23 without the exon 68 peptide (compare $\boldsymbol{L}$ with $\boldsymbol{C}$; and see Results), elimination of the four-residue C-terminal PBM from FLAG-Cdh23 with the exon 68 peptide $[C d h 23(+68) \Delta C 4]$ does not decrease GFP-harmonin a1 (harm) colocalization in microvilli (compare $\boldsymbol{N}-\boldsymbol{P}$ with $\boldsymbol{K}-\boldsymbol{M}$ ). Scale bar (in $\boldsymbol{A}$ ): $\boldsymbol{A}-\boldsymbol{P}, 10 \mu \mathrm{m}$.

prevailing model for harmonin-Cdh23 interactions (Siemens et al., 2002; Müller, 2008), we were surprised to find no decrease in microvillar colocalization after deleting the Cdh23 C-terminal class I PBM (Fig. 1 B), consisting of the four-residue peptide -ITEL. In fact, the $\mathrm{H} / \mathrm{C}$ ratios in microvilli for the $\mathrm{Cdh} 23$ and $\mathrm{Cdh} 23 \Delta \mathrm{C} 4$ constructs were not significantly different $(1.0 \pm 0.2$ and $1.1 \pm 0.2 ; p=0.07)$ (Fig. $4 B-D, H-J$ ). Thus, if colocalization in microvilli reflected the binding of GFP-harmonin a1 to FLAG-Cdh23, this result suggested that the majority of the harmonin binding was mediated through an internal binding site, upstream in the Cdh23 cytoplasmic tail. There was also no decrease in colocalization observed after deleting the Cdh23 C-terminal PBM when the Cdh23 included the 35-residue exon 68 peptide, Cdh23(+68). The exon 68 peptide is inserted approximately in the middle of the cytoplasmic tail (Fig. $1 B$ ) and present in a significant fraction of in-

ner ear Cdh23 (Di Palma et al., 2001b; Siemens et al., 2002). We did, however, consistently observe a decrease in the level of anti-FLAG immunolabeling in cells expressing Cdh23(+68). Compared with FLAG-Cdh23, we measured an approximately threefold decrease in FLAG antibody labeling intensity for cells expressing FLAG-Cdh23 $(+68)(1.0 \pm 0.3$ vs $0.3 \pm$ $0.1 ; p<0.0001)$. This decrease reduced the signal in the microvillar colocalization assay and increased the SD of fluorescence intensity measurements. It is for this reason that our transfection experiments featured the isoform of $\mathrm{Cdh} 23$ without the exon 68 peptide. The $\mathrm{H} / \mathrm{C}$ ratios in microvilli for the Cdh23 $(+68)$ and $\mathrm{Cdh} 23(+68) \Delta \mathrm{C} 4$ constructs were not significantly different $(1.0 \pm 0.5$ and $1.3 \pm$ $0.6 ; p=0.06$ ) (Fig. $4 K-P$ ).

Colocalization with microvillar Cdh23 and the lack of a decrease in colocalization after deleting the Cdh23 C-terminal PBM were also noted for a larger harmonin isoform, harmonin b1. The harmonin b isoforms, which have been called actinbundling proteins of stereocilia (Boëda et al., 2002), differ from the harmonin a isoforms by including an additional predicted coiled-coil domain and a proline, serine, threonine-rich domain between the PDZ2 and PDZ3 domains (Verpy et al., 2000) (Fig. 1C). Harmonin b has been found to change its localization from all along stereocilia to stereocilia tips to the region of the tip link as maturation proceeds (Boëda et al., 2002; Lefèvre et al., 2008), and Grillet et al. (2009) and Michalski et al. (2009) have suggested recently that harmonin $\mathrm{b}$ is required to form upper tip-link densities and for normal hair cell mechanoelectrical transduction. When expressed without Cdh23 in CL4 cells, harmonin b1 was not detected in microvilli but did become concentrated in two other F-actin-rich structures: a beltlike accumulation at the lateral margin and a lacy cytoplasmic network, which occupied variable portions of the cytoplasm (Fig. 5A-C). The lacy cytoplasmic network, which is prominent in the left half of the cell shown in Figure $5 A-C$, had no obvious counterpart in cells not transfected with harmonin b1. The lateral belt, which was positioned along the apical half of the lateral domain (Fig. $5 A^{\prime}-$ $C^{\prime}$; an $x, z$ orthogonal section through the right half of the cell in $A-C)$, appeared to be an exaggerated version of the F-actincontaining junctional belt normally present at this location (Fig. $2 B, C)$. The ability of harmonin b2 (Boëda et al., 2002) and an unspecified harmonin b isoform (Grillet et al., 2009) to form and be targeted to large cytoplasmic F-actin bundles in transfected HeLa cells was noted previously. Remarkably, coexpression with Cdh23 caused a large fraction of the harmonin b1 to become colocalized with Cdh23 in CL4 cell microvilli (Fig. 5D-F), dramatically reducing its tendency to form, and accumulate in, the 
lateral belt and lacy cytoplasmic network. As was the case for harmonin a1, deletion of the Cdh23 C-terminal PBM did not reduce the level of colocalization of harmonin b1 in CL4 cell microvilli. For harmonin $\mathrm{b} 1$, the $\mathrm{H} / \mathrm{C}$ ratios in microvilli for

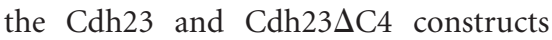
were not significantly different $(1.1 \pm 0.1$ and $1.0 \pm 0.2 ; p=0.08$ ) (Fig. $5 D-I$ ).

We considered the possibility that our inability to detect a significant role for the Cdh23 C-terminal PBM reflected competition with some endogenous protein in CL4 cells. To circumvent this potential complication, we examined binding interactions between affinity purified recombinant harmonin a1 and Cdh23 tail protein constructs in vitro. These in vitro binding assays confirmed the results of our CL 4 cotransfection assays. Deletion of the Cdh23 PBM had no significant effect on harmonin al binding, again suggesting that the majority of the harmonin binding was mediated by an internal binding site, upstream in the Cdh23 cytoplasmic tail. This was the case with (Fig. $6 A$, lanes a, b) and without (Fig. $6 A$, lanes $\mathrm{c}, \mathrm{d}$ ) the exon 68 peptide (Fig. $6 B)(p>0.05$ for both comparisons). Remarkably, it was possible to detect very slight decreases in apparent molecular mass for the $\Delta \mathrm{C} 4 \mathrm{Cdh} 23$ tail constructs relative to their full-length Cdh23 tail counterparts (Fig. 6A, lanes a-d). These decreases, which became more pronounced when gels were run for longer times, supplied supporting biochemical evidence for the presence of the C-terminal peptides in the affinity-purified Cdh23 tail proteins: if the $\mathrm{C}$ termini had been lost from the GST-Cdh23 tail proteins as a result of partial proteolysis, then deletion of the C-terminal PBM would not be expected to decrease apparent molecular mass. Furthermore, contrary to a previous report showing that harmonin binding to an internal site in the Cdh 23 tail is reduced $\sim 10$-fold by inclusion of the exon 68 peptide (Siemens et al., 2002), the levels of harmonin binding by the $\mathrm{Cdh} 23$ and $\mathrm{Cdh} 23(+68)$ tail constructs were not significantly different (Fig. $6 A$, lanes a, $c ; B)(p>0.05)$.

We found that we could delete much larger peptides from the $\mathrm{C}$ terminus of the Cdh23 cytoplasmic tail, even up to 108 residues, without causing a significant decrease in harmonin al binding (Fig. 6A, lanes c, f; B) $(p>0.05)$. Deletion of the C-terminal 108 aa makes a Cdh23 construct that ends immediately $\mathrm{N}$ terminal to site of inclusion of the exon 68 peptide (Fig. $1 \mathrm{~B}$ ). Correspondingly, the $\mathrm{H} / \mathrm{C}$ ratio in CL4 cell microvilli for the Cdh23 and Cdh $23 \Delta \mathrm{C} 108$ constructs were indistinguishable $(1.0 \pm 0.2$ and $1.0 \pm 0.2 ; p=0.6)$ (Figs. $4 B-D, 5 J-L)$. Additional truncation of 35 aa from the $C$ terminus of the Cdh23 cytoplasmic tail to make Cdh23 $\Delta$ C143, however, resulted in an $\sim 100$-fold decrease in harmonin al binding (Fig. bar in $\mathbf{D}$ applies to $\mathbf{D}-\mathbf{0})$.
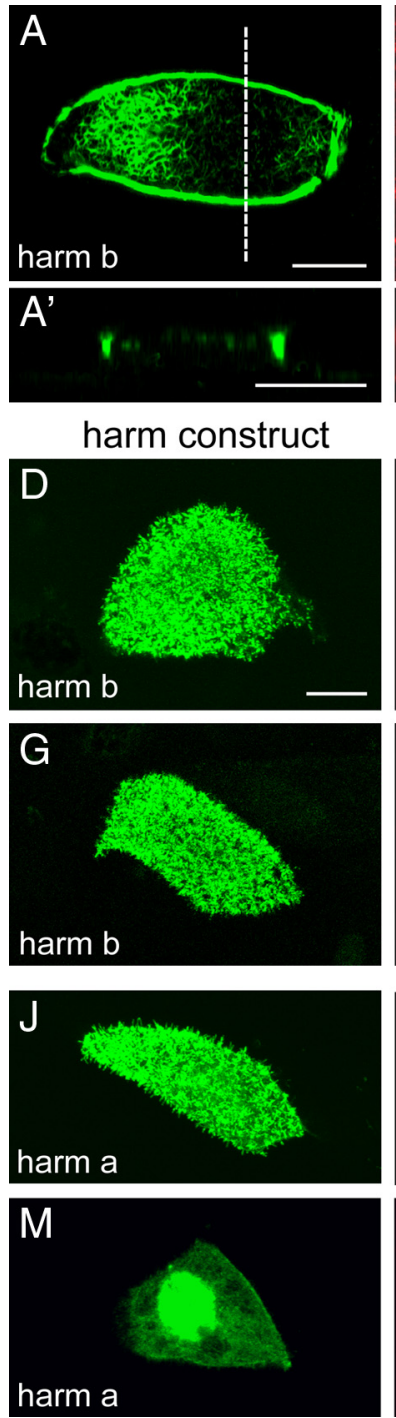
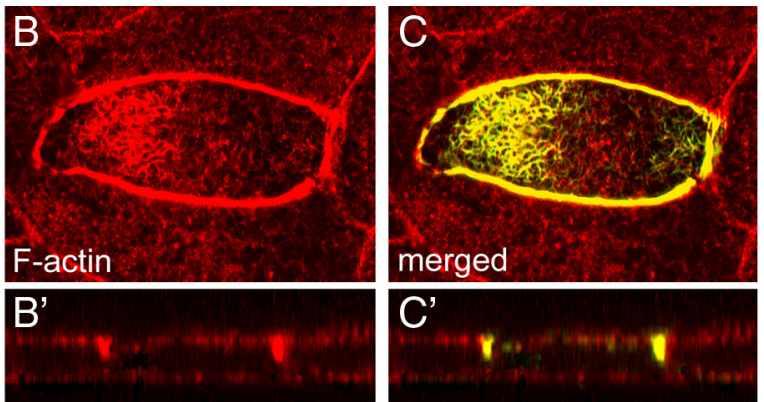

Cdh23 construct
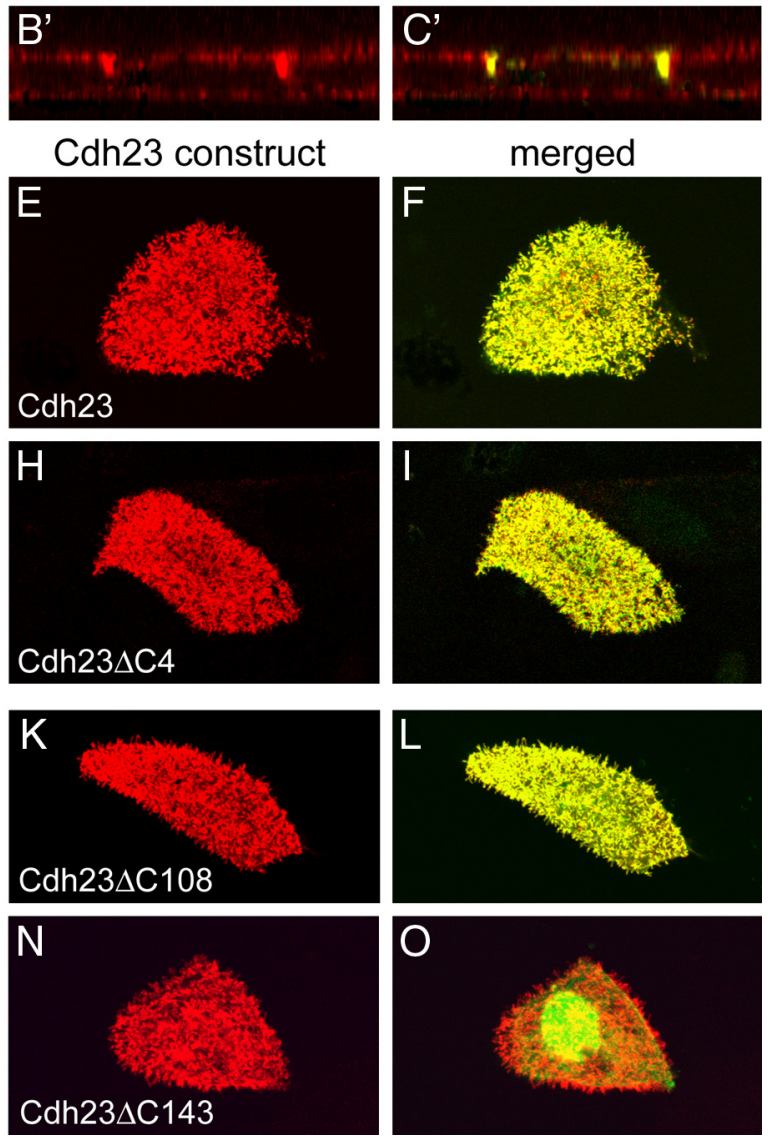

Figure 5. Colocalization of harmonin b1 with microvillar Cdh23 and mapping the harmonin a1 binding site on the Cdh23 cytoplasmic tail using the colocalization assay. $\boldsymbol{A}-\boldsymbol{C}$, When expressed without FLAG-Cdh23, GFP-harmonin b1 (harm b) does not accumulate in microvilli but becomes colocalized with F-actin in a belt-like accumulation at the lateral margin and in a lacy cytoplasmic network (prominent in left half of cell), as revealed by labeling with Texas Red-X phalloidin ( $\boldsymbol{B})$. Dashed line in $A$, Plane of $x, z$ orthogonal section shown in $A^{\prime}-C^{\prime} . A^{\prime}-C^{\prime}, A 1.5 \times$ enlarged $x, z$ orthogonal section through the right half of the transfected cell shown in $A-C$ (along dashed line in $A$ ) highlighting the accumulation of GFP-harmonin b1 and F-actin in what appears to be an exaggerated version of the F-actin-containing junctional belt normally present near the apical end of the lateral domain. $\boldsymbol{D}-\boldsymbol{F}$, When coexpressed with FLAG-Cdh23 (Cdh23), a large fraction of GFP-harmonin b1 (harm b) colocalizes with FLAG-Cdh23 in microvilli, suggestive of binding between the two expressed proteins, and is no longer prevalent in a lateral belt-like accumulation or lacy cytoplasmic network. G-I, Elimination of the four-residue C-terminal PBM from FLAG-Cdh23 (Cdh23 $\Delta$ C4) does not decrease GFP-harmonin b1 (harm b) colocalization in microvilli (compare with D-F). J-L, Elimination of the 108 residues from the $C$ terminus of FLAG-Cdh23 (Cdh23 $\Delta C 108)$ does not decrease GFP-harmonin a1 (harm) colocalization in microvilli (compare with Fig. $4 B-D$ ). $\mathbf{M}-\mathbf{0}$, Elimination of 143 residues from the $C$ terminus of FLAG-Cdh23 (Cdh23 $\Delta$ C143) drastically reduces colocalization of GFP-harmonin a1 (harm) in microvilli. Instead, the GFP-harmonin a1 returns to the nucleus and cytoplasm (compare $\boldsymbol{M}$ to Fig. $4 \mathrm{~A}$ ), and the merged image changes from yellow to red-orange $(\mathbf{0})$. Scale bars, $10 \mu \mathrm{m}$ (scale

$6 A$, lanes $c, g ; B)(p<0.001)$ to a level comparable with the background binding observed with GST alone (Fig. 6A, lane h). Likewise, in cotransfected CL4 cells, deletion of the 143-residue C-terminal peptide from the Cdh23 tail brought about a dramatic loss of GFP-harmonin a1 from microvilli and its return to the nucleus (Fig. $5 \mathrm{M}$ ), although the $\mathrm{Cdh} 23 \Delta \mathrm{C} 143$ construct was still efficiently targeted to microvilli (Fig. $5 N$ ). In fact, the intensities of live-cell anti-FLAG immunolabeling at $0-1^{\circ} \mathrm{C}$ observed for cells transfected with the Cdh23 and Cdh $23 \Delta \mathrm{C} 143$ constructs were indistinguishable $(1.0 \pm 0.3$ and $1.0 \pm 0.3 ; p=0.7)$. The 
A

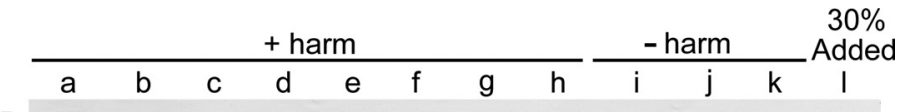

$115-$

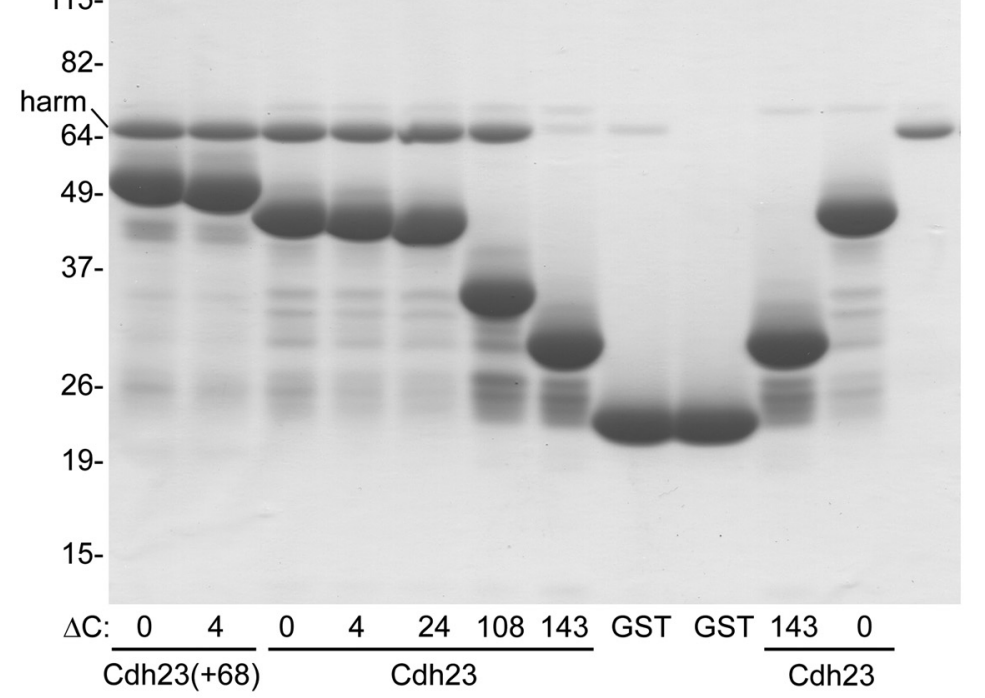

$\mathrm{B}$

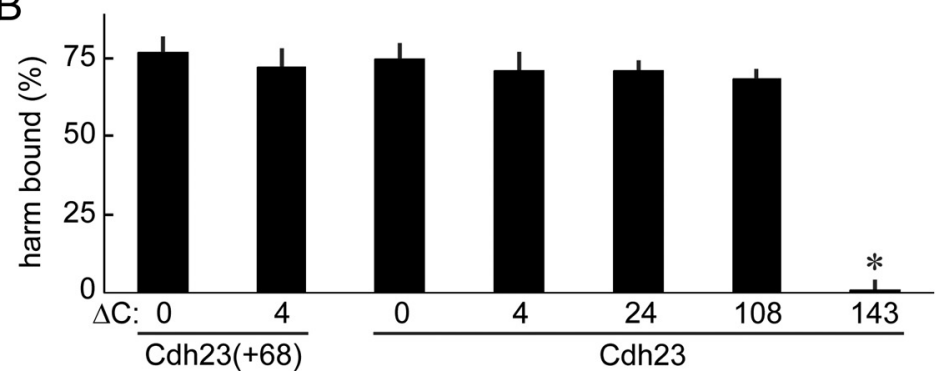

Figure 6. Mapping the harmonin a1 binding site on the Cdh23 cytoplasmic tail using the in vitro binding assay. A, A Coomassie blue-stained SDS gel shows the results of representative in vitro binding assays between purified 6 xHis-harmonin a1 protein (harm) and the designated purified GST-Cdh23 cytoplasmic tail protein, or GST alone, immobilized on glutathione-Sepharose 4B beads. GST-Cdh23 cytoplasmic tail constructs either include $[\mathrm{Cdh} 23(+68)]$ or exclude $(\mathrm{Cdh} 23)$ the exon 68 peptide and are missing the designated number of amino acid residues from their $C$ terminus $(\Delta C)$. Lanes $i-k$ contain control samples that exclude harmonin protein to illustrate that bands comigrating with harmonin are not present in any of the GST-Cdh23 tail proteins. Lane I contains $30 \%$ of the harmonin protein input into the binding assay. The numbers at left indicate the positions of apparent molecular mass markers in kilodaltons. $\boldsymbol{B}$, Graph showing results of three independent in vitro binding assays like that shown in $\boldsymbol{A}$. The mean levels of harmonin (harm) bound to the designated constructs are plotted as a percentage of the amount of harmonin added to the binding assay. Error bars represent +1 SD. The Tukey-Kramer multiple comparisons test indicated that the means are not significantly different from each other ( $p>0.05$ ) except during comparison with $\operatorname{Cdh} 23 \Delta C 143\left({ }^{*} p<0.001\right)$. Note that elimination of the four-residue C-terminal PBM of $\Delta C 4$ does not diminish harmonin binding with or without the exon 68 peptide, GST-Cdh23 tail constructs with and without the exon 68 peptide bind similar levels of harmonin, deletion of up to 108 residues $(\Delta C 108)$ does not diminish harmonin binding, and deletion of 143 residues $(\Delta C 143)$ drastically reduces binding to near the background level observed with GST alone.

GFP-harmonin localization pattern observed during coexpression with the Cdh $23 \Delta \mathrm{C} 143$ construct was highly similar to that observed for GFP-harmonin a1 in the absence of Cdh23 (Fig. $4 A$ ), and this caused a change from yellow to red-orange in the merged image (Fig. 5O). These results suggested that the harmonin al binding site mapped to the 35 -aa internal peptide $\mathrm{P} 3177$ K3211 in the cytoplasmic tail of Cdh23 (Fig. 1B).

According to the prevailing model, the Cdh23 C-terminal PBM (Fig. $1 B$ ) is believed to bind to the harmonin PDZ2 domain (Siemens et al., 2002; Grillet et al., 2009; Pan et al., 2009). However, consistent with our findings of a minor role for the Cdh23 C-terminal PBM, we found that an N-terminally truncated harmonin al construct, which contained the PDZ2 and PDZ3 domains but was missing the $\mathrm{N}$ and PDZ1 domains (Fig. 1C), did not show significant microvillar colocalization with FLAG-
Cdh23 in cotransfected CL4 cells (Fig. $7 A-C)$. In contrast, the other segment of harmonin al, consisting of the $\mathrm{N}$ domain and PDZ1 domain (Fig. 1C), showed high levels of microvillar colocalization with FLAG-Cdh23 (compare Fig. 7D-F with Fig. $\left.4 B^{\prime}-D^{\prime}\right)$. This suggested that the main binding site for the Cdh23 tail resided in the $\mathrm{N}$ domain or PDZ1 domain of harmonin a1. Structural analysis of multiple PDZ-PBM complexes has implicated a conserved binding pocket or groove within the PDZ domain that involves the carboxylate-binding loop, including several residues of the $\beta \mathrm{B}$ strand, and a downstream histidine in helix $\alpha \mathrm{B}$ (Doyle et al., 1996; Harris and Lim, 2001). Unexpectedly, we found that deletion of the PDZ-binding pocket of the harmonin a1 PDZ1 domain (92-RLHPEGLGLSVR103), including mutation of the corresponding histidine residue (H147) to alanine, did not decrease colocalization with FLAG-Cdh23 in CL4 cell microvilli (compare Fig. $7 G-I$ with Fig. $4 B-D$ ). In fact, it brought about an $\sim 30 \%$ increase in the $\mathrm{H} / \mathrm{C}$ ratio in microvilli (from $1.0 \pm$ 0.2 to $1.3 \pm 0.2 ; p<0.0001)$. This result suggested that the interaction was not a conventional PDZ domain interaction. Removal of the harmonin $\mathrm{N}$ domain did, however, bring about a dramatic loss of GFP-harmonin a1 from microvilli and its return to the nucleus (Fig. 7J-L), like the situation described above for the Cdh23 $\Delta$ C143 tail construct (Fig. 5M-O). It was not possible to confirm the effects of these strategic harmonin al mutations in the in vitro binding assay, as we had done above for the Cdh23 tail mutations (Fig. 6), because the mutations in question severely compromised the recovery or solubility of the harmonin al protein when expressed in E. coli. Together, our mutagenesis studies suggested that the predominant interaction between harmonin a1 and Cdh 23 involved the harmonin

$\mathrm{N}$ domain and the relatively short internal peptide P3177-K3211 in the Cdh23 cytoplasmic tail. Although there is a formal possibility that abolition of binding activity via mutagenesis can be a consequence of protein misfolding, our conclusions regarding binding site identification are reinforced by the recent work of Pan et al. (2009), who detected an interaction between the harmonin $\mathrm{N}$ domain and a similar internal peptide in the Cdh23 cytoplasmic tail using a different, nuclear magnetic resonance-based three-dimensional structural approach.

\section{Espin-elongated microvilli of CL4 cells and myosin XVa targeting}

During heterologous expression in CL4 cells, the espin actinbundling proteins of hair cell stereocilia (L. Zheng et al., 2000) are efficiently targeted to CL4 cell microvilli and increase 
steady-state microvillar length by causing a concentration-dependent elongation of the parallel actin-bundle scaffold at the microvillar core (Loomis et al., 2003). Espins are more potent than other actin-bundling proteins at eliciting microvillar elongation (Loomis et al., 2003), possibly because of their high affinity for F-actin (Chen et al., 1999) and their highly cooperative effects on actin filament twist (Shin et al., 2009). Transfection with espin plasmid increases average microvillar length from the $1.3 \pm 0.5 \mu \mathrm{m}$ value measured in control cells to $8 \pm 2 \mu \mathrm{m}$ (mean $\pm \mathrm{SD}$; range, 3.5-17 $\mu \mathrm{m}$ ) (Loomis et al., 2003), resulting in collections of parallel actin-bundle-containing fingerlike protrusions that more closely resemble stereocilia in length (Fig. 8A). For example, the longest stereocilia on hamster inner hair cells and mouse utricular hair cells are $\sim 5$ and $\sim 13 \mu \mathrm{m}$, respectively (Kaltenbach et al., 1994; Li et al., 2008). Although espin-elongated microvilli often appear thicker than the microvilli of neighboring control cells in confocal images (Fig. 8A), this effect has not been studied systematically and could partly reflect microvillar aggregation. In electron micrographs, espin-elongated microvilli show diameters in the 100-200 nm range (Loomis et al., 2003), which is thinner than some stereocilia $[\sim 400 \mathrm{~nm}$ on hamster inner hair cells (Kaltenbach et al., 1994)] but similar to others, e.g., in chicken cochlea [110-190 nm (Tilney et al., 1986)] and on rat outer hair cells $[\sim 200 \mathrm{~nm}$ (Furness et al., 2008)]. The 116-aa C-terminal actin-bundling module of the espins, which contains novel F-actin-binding sites disposed approximately at either end (Bartles et al., 1998) (Fig. 1D), is necessary and sufficient for the microvillar elongation activity (Loomis et al., 2003). Other parts of the espins, including their actin monomerbinding WH2 domain, are not required (Loomis et al., 2003, 2006). We examined the effects of two mutations that affect the espin C-terminal actin-bundling module and are associated with recessive deafness and vestibular dysfunction in humans (DFNB36) (Naz et al., 2004). The mutation c.2469delGTCA, which causes a frame shift predicted to eliminate the C-terminal F-actin binding site of the espin actin-bundling module (p.Q823fsX845) (Fig. 1D), resulted in a protein that retained only weak microvillar targeting and elongation activity, evident primarily near the cell periphery (Fig. $8 \mathrm{~B}$ ). The bulk of this mutated espin was detected in the junctional belt, nucleus, and cytoplasm (Fig. 8B). The mutation c.1988delAGAG, which causes a frame shift predicted to eliminate the entire espin F-actin-bundling module (p.G662fsX664) (Fig. 1D), resulted in a protein that failed to target or elongate microvilli in the transfected CL4 cells and appeared to concentrate in nuclei instead (Fig. 8C).

To demonstrate that espin-induced microvillar elongation greatly enhances spatial resolution for the confocal imaging of expressed stereociliary proteins, we examined the unconventional myosin motor myosin XVa. This barbed-end-directed unconventional myosin motor normally moves along the core actin bundle to accumulate at the stereocilium tip (Belyantseva et al., 2003, 2005) and is
PDZ2 + PDZ3
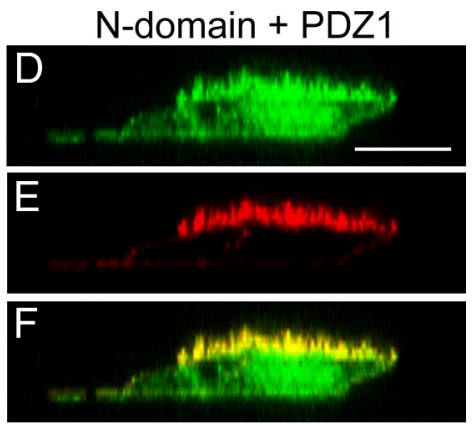

Cdh23
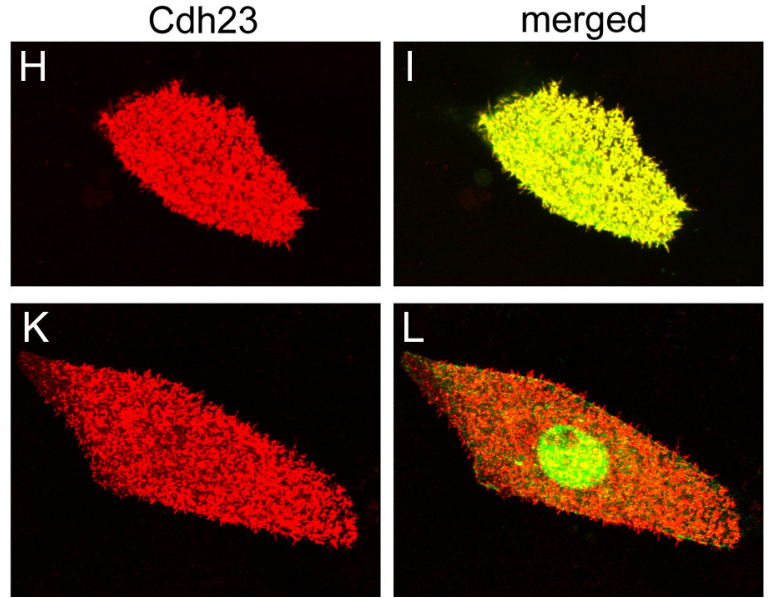

Figure 7. Mapping the Cdh23 binding site on harmonin a1 using the colocalization assay. $\mathbf{A}-\mathbf{C}$, GFP-harmonin a1 (harm) missing the N domain and PDZ1 domain (PDZ2 + PDZ3) does not colocalize with FLAG-Cdh23 (Cdh23) in microvilli. D-F, A large 作 with FLAG-Cdh23 (Cdh23) in microvilli. Instead, the GFP- harmonin a1 construct returns to the nucleus and cytoplasm (compare $\boldsymbol{J}$ with Fig. $4 A$ ), and the merged image changes from yellow to red-orange $(\boldsymbol{L})$. Scale bars, $10 \mu \mathrm{m}$ (scale bar in $\mathbf{G}$ applies to $\mathbf{G}-\boldsymbol{L}$ ).

believed to operate in a common pathway with a known protein cargo, whirlin, to regulate postnatal stereocilium elongation (Mburu et al., 2003; Belyantseva et al., 2005; Delprat et al., 2005). During heterologous expression in CL4 cells, GFP-myosin XVa was observed in tiny puncta at or near the tips of the brush border microvilli (Fig. 8D). Because of the small size of CL4 cell microvilli, however, this localization was clearly evident only in rare, advantageous images. Note that transfection with GFP-myosin XVa had no obvious effect on microvillar length (Fig. 8D). However, when GFP-myosin $\mathrm{XVa}$ was coexpressed with untagged espin, which brings about its usual microvillar elongation, the accumulation of GFP-myosin XVa at microvillar tips became strikingly more evident (Fig. $8 E$ ) and reminiscent of the localization of myosin XVa observed in hair cell stereocilia (Belyantseva et al., 2003, 2005).

We used the tip accumulation of GFP-myosin XVa to examine the effects on localization of some recently identified recessive mutations of myosin XVA associated with severe-to-profound recessive hearing loss in humans (DFNB3) (Nal et al., 2007). To our knowledge, in vitro motility assays have not yet been developed for myosin XVa. We selected for study three missense mutations that affected motor domain amino acids that are identical in $\sim 90 \%$ of 143 myosins, including mouse myosin XVa (Cope et al., 1996) (T. Hodge and M. J. T. V. Cope, Medical Research Council Laboratory of Molecular Biology, Cambridge, UK; www.mrc-lmb. cam.ac.uk/myosin/trees/txalign.html): c.4351G $>$ A (p.D1451N), c.4669A $>$ G (p. K1557E), and c.5117-5118GC $>$ TT (p.G1706V) 

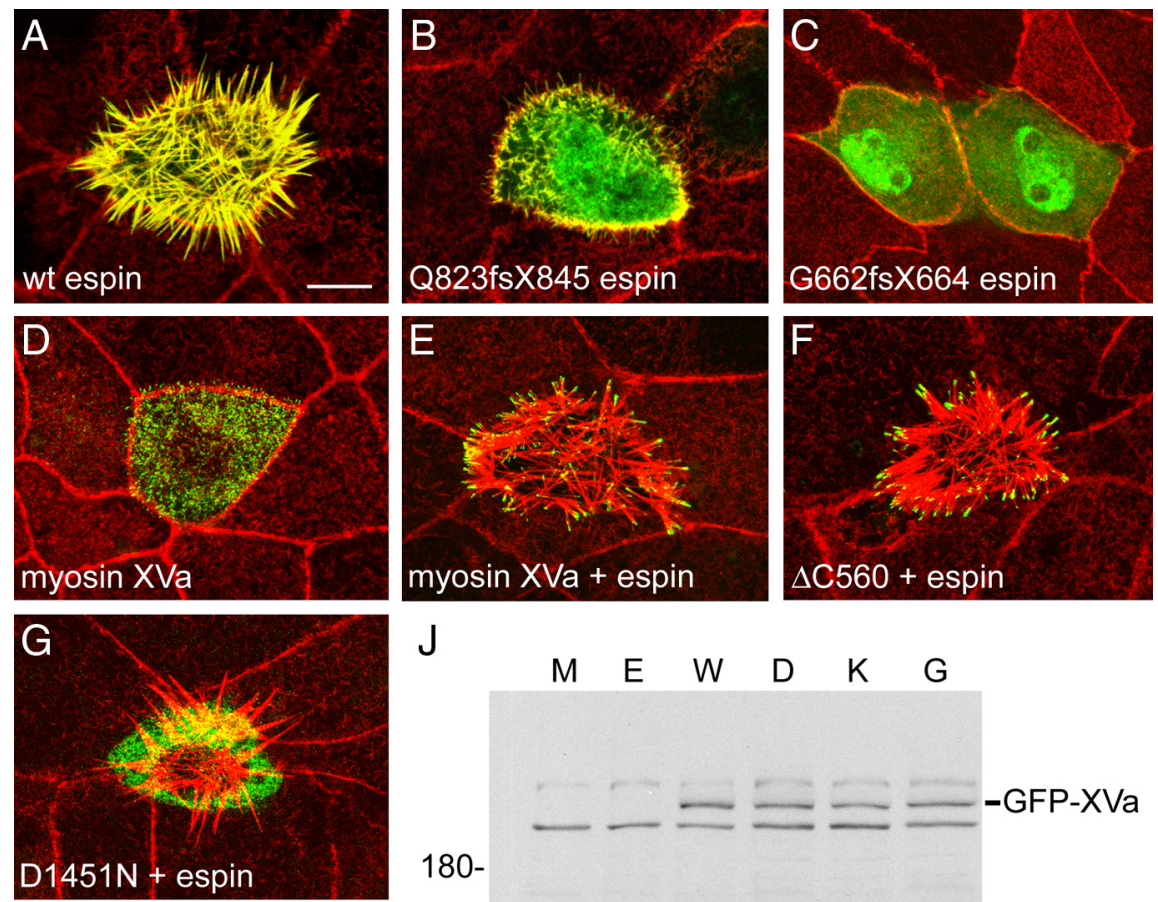

$J$
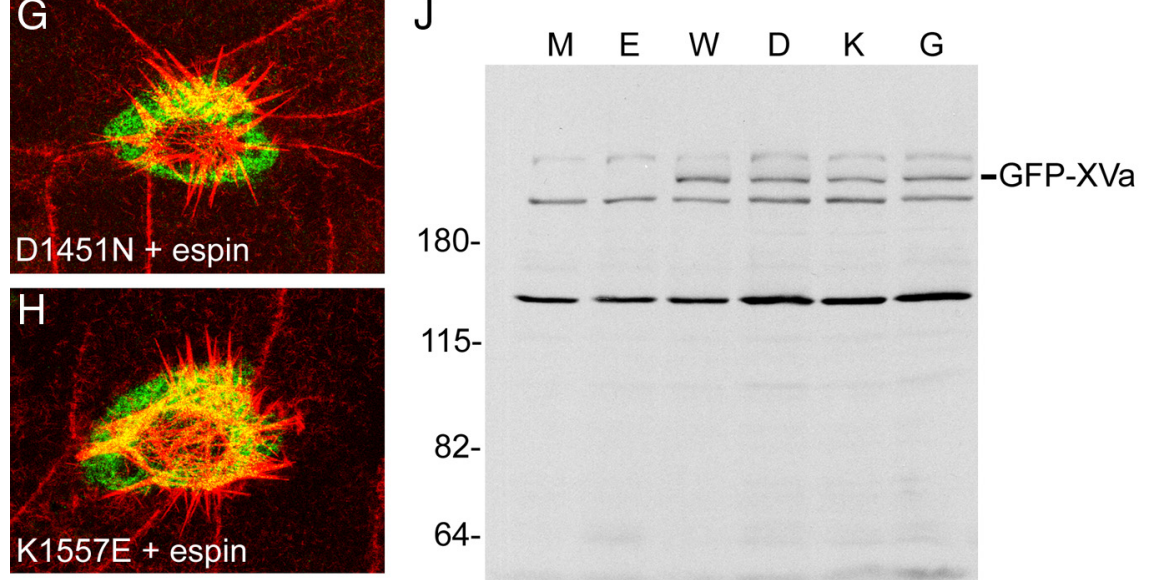

$115-$

82-

64-
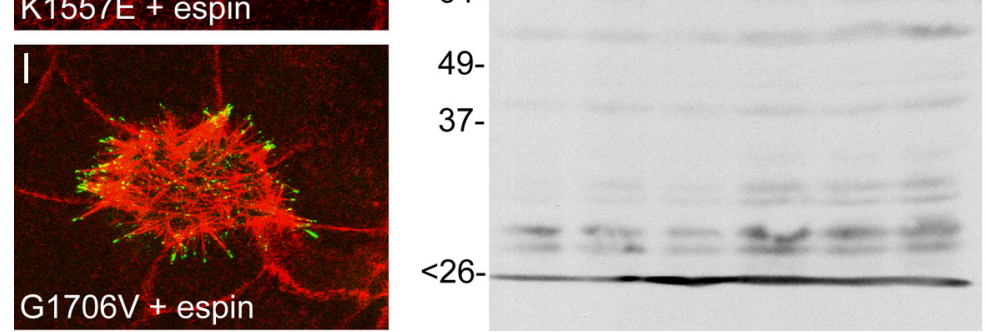

Figure 8. Examining human espin and myosin XVa deafness mutations using espin-mediated microvillar elongation. $A-I$ are labeled with Texas Red-X phalloidin to reveal F-actin and highlight the actin bundles of $\mathrm{CL} 4$ cell microvilli. $A$, Wild-type GFP-espin (wt espin) is efficiently targeted to microvillar actin bundles and causes pronounced microvillar elongation (average microvillar length, $7 \pm 1 \mu \mathrm{m}$ for this cell). $\boldsymbol{B}$, GFP- espin with the c.2469delGTCA human deafness mutation (Q823fs X845 espin) retains only weak microvillar targeting and elongation activity, evident mainly near the cell periphery. This mutated espin accumulates in the junctional belt, nucleus, and cytoplasm. C, GFP-espin with the c.1988delAGAG human deafness mutation (G662fsX664 espin) neither targets microvilli nor causes microvillar elongation and instead accumulates in the nucleus. This localization does not reflect recent cell division, because individual transfected cells look the same. D, GFP-myosin XVa (myosin XVa) accumulates at the tips of brush border microvilli, but this is difficult to resolve because the microvilli are small. $\boldsymbol{E}$, When coexpressing GFP-myosin XVa and untagged espin (myosin XVa + espin), GFP-myosin XVa accumulates at the tips of the espin-elongated microvilli. Compared with the situation without espin $(\boldsymbol{D})$, tip accumulation is much easier to discern. $\boldsymbol{F}$-I, The transfected cells are coexpressing GFP-myosin $X V a$ with the designated mutation and untagged espin (+espin). Accumulation at the tips of espin-elongated microvilli is observed for GFP-myosin XVa missing the C-terminal 560 residues $(\Delta C 560 ; \boldsymbol{F})$ and GFP-myosin XVa with the G1706V human deafness mutation $(\boldsymbol{I})$ but is not observed for GFP-myosin XVa with the D1451N $(\boldsymbol{G})$ or the K1557E $(\boldsymbol{H})$ human deafness mutation. The latter two constructs are concentrated below, in the cytoplasm $(\boldsymbol{G}, \boldsymbol{H})$. Average microvillar length is similar for the transfected cells shown in $\boldsymbol{E}-\boldsymbol{I}(8 \pm 1-2 \mu \mathrm{m})$. Scale bar (in $\boldsymbol{A})$ : $\boldsymbol{A}-\boldsymbol{I}, 10 \mu \mathrm{m}$. $\boldsymbol{J}$, A representative GFP antibody-labeled Western blot of SDS extracts prepared from CL 4 cells cotransfected with the untagged espin construct and the designated GFP-myosin XVa construct shows that there is no change in apparent molecular mass or major difference in expression levels or integrity among the GFPmyosin XVa protein bands (GFP-XVa) examined in $\boldsymbol{E}$ and $\mathbf{G}$-I: wild-type (lane W), D1451N (lane D), K1557E (lane K), G1706V (lane $G)$. When applied to the results of three independent Western blotting experiments, the Dunnett's multiple comparisons test indicates that mean band intensities for the mutated GFP-myosin XVa proteins are not significantly different from those of the wild-type control ( $p>0.05$ ). The bands other than the GFP-myosin XV band (GFP-XVa) are background bands, which are also present in SDS extracts prepared from mock-transfected cells (lane $M$ ) and cells transfected with the untagged espin construct alone (lane E). The numbers at left indicate the positions of apparent molecular mass markers in kilodaltons. (numbering refers to the human isoform 1 as in the study by $\mathrm{Nal}$ et al., 2007) (Fig. $1 E)$. On the basis of sequence alignment with the motor domain of myosin II, D1451 and K1557 are expected to be in the upper domain of the $50 \mathrm{kDa}$ fragment, in the beginning of helix $\mathrm{K}$ and middle of helix O, respectively, and G1706 is expected to be in the lower domain of the 50 $\mathrm{kDa}$ fragment, in which it would border the wedge loop and be near the $\mathrm{SH} 2$ helix and the interface between the 50 and 20 $\mathrm{kDa}$ fragments (Cope et al., 1996; Geeves and Holmes, 1999). Outside of being highly conserved, D1451 and K1557 were not suspected to be required for myosin motor function, although a missense mutation at the residue in human $\beta$-cardiac myosin corresponding to G1706 (G584R) had been associated with familial cardiomyopathy (Rayment et al., 1995). The selected mutations were introduced into the GFP-myosin XVa construct, and their effects on localization were observed in CL4 cells cotransfected with untagged espin. Two of the mutations, D1451N and K1557E, blocked the accumulation of GF$\mathrm{P}-\mathrm{myosin} \mathrm{XVa}$ at microvillar tips, suggesting that these mutations significantly impaired motor activity (Fig. 8G,H). Instead, these proteins accumulated in the cytoplasm (Fig. 8G,H). However, one of the three mutations tested, G1706V, seemed to have no effect, because this protein accumulated at the tips of the espinelongated microvilli (Fig. 8I) like wildtype GFP-myosin XVa (Fig. 8E). We checked the integrity of the expressed GF$\mathrm{P}-\mathrm{myosin} \mathrm{XV}$ a proteins on Western blots prepared from SDS extracts of the cotransfected CL4 cells. The GFP-myosin $\mathrm{XVa}$ proteins, both wild-type and mutated, are expressed at lower levels than many other proteins we have examined in CL4 cells and are also of relatively high molecular mass ( $290 \mathrm{kDa})$. Nevertheless, on Western blots labeled with GFP antibody, it was possible to distinguish the GFP-myosin XVa bands from the nonspecific background bands that were present in the mock-transfected cells and in cells transfected with untagged espin plasmid alone (Fig. $8 \mathrm{~J}$ ). Importantly, we detected no change in apparent molecular mass, integrity, or expression level among the GFP-myosin XVa proteins tested that could account for the differences in microvillar tip localization observed. The mean intensities of the GFPmyosin XVa bands measured for the mutated constructs in three independent experiments were highly similar to each other (92-94 $\pm 13-15 \%$ of control) and 
did not differ significantly from the wild-type control ( $p=0.9$ ). Finally, we considered the possibility that the mutated GFP-myosin XVa proteins had experienced a minor proteolytic cleavage that was not detectable on Western blots. We dismissed the possibility of minor proteolysis at the $\mathrm{N}$ terminus, because this would have affected the GFP, yet the proteins reacted with GFP antibody on Western blots and exhibited the green fluorescence characteristic of GFP. To examine the consequences of proteolysis at the $\mathrm{C}$ terminus, we compared the localization of wild-type GFP-myosin XVa that was missing 560 aa from its tail, including the C-terminal MyTH4 domain, FERM domain, and PBM (Fig. 1 E). This C-terminally truncated GFP-myosin XVa accumulated at the tips of the espin-elongated microvilli (Fig. $8 F$ ) like the intact GFP-myosin XVa (Fig. 8E). This result reduced the likelihood that minor proteolysis at the $\mathrm{C}$ terminus could impact accumulation at the microvillar tip. Thus, our experiments suggested that the D1451N and K1557E mutations associated with recessive deafness in these families markedly inhibited the motor activity of myosin XVa.

\section{Discussion}

Our findings indicate that the CL4 cell transfection model can be a valuable addition to immunocytochemistry, hair cell transfection, and the analysis of mutant mice when studying the targeting, interactions, and mutations of hair cell proteins. As easy to use as standard heterologous expression systems with nonpolarized cells, the CL4 cell model often yields important additional information as a result of the enhanced spatial resolution between subcellular compartments. It can be of special merit for the rapid screening of wild-type versus mutated constructs or to circumvent complications resulting from high-level endogenous expression in hair cells.

Heterologous expression of membrane proteins with multiple membrane-spanning domains can be challenging. In CL4 cells, we achieved efficient domain-specific plasma membrane targeting for tagged versions of the SLC26 family members prestin and pendrin, which are believed to contain $\geq 10$ membrane-spanning domains and were targeted to opposite plasma membrane domains. The intracellular accumulation we observed for start-21 and stop-709 prestin constructs suggests that residues 1-20 and $710-744$ at the $\mathrm{N}$ and $\mathrm{C}$ termini, respectively, are required for the efficient surface delivery of prestin in epithelial cells. The basolateral targeting we observed for prestin in CL4 cells and the LLCPK1 parental line argues against a tyrosine-based basolateral sorting motif (Fölsch, 2005), and our transplantation experiment examining the pendrin-prestin chimera suggests that the 247residue cytoplasmic tail of prestin contains a dominant basolateral targeting motif (Carmosino et al., 2010) that is responsible for targeting this physiologically important protein to the basolateral plasma membrane domain.

In CL4 cells, we achieved coexpression of tagged versions of the link-associated atypical cadherin Cdh23 and its cytoplasmic binding protein harmonin. The Cdh23 was efficiently targeted to the CL4 cell microvillar membrane, the topological equivalent of the stereociliary membrane, and, in coexpressing cells, a large fraction of the harmonin became colocalized with Cdh23 in microvilli. This robust signal in the biologically correct subcellular compartment represents an improvement over colocalization in undefined cytoplasmic structures in cotransfected HeLa cells (Pan et al., 2009). Using a combination of CL4 cell cotransfection and in vitro binding assays, we found the dominant binding interaction between Cdh23 and harmonin to involve a 35-aa internal peptide (P3177-K3211) in the Cdh23 cytoplasmic tail and the
N-terminal part of harmonin but surprisingly not the PDZ1 domain binding pocket. The fact that the $\mathrm{P} 3177-\mathrm{K} 3211$ peptide is $\mathrm{N}$ terminal to the site of insertion of the exon 68 peptide (Fig. $1 B$ ) likely explains our finding that similar levels of harmonin were bound to the Cdh23 tail in vitro with or without the exon 68 peptide. This finding contradicts the prevailing model for interactions between these key proteins of the Usher interactome (Müller, 2008): using coupled in vitro transcription-translation pulldowns and cotransfection coimmunoprecipitations, Siemens et al. (2002) found that inclusion of the exon 68 peptide reduced harmonin binding to the internal binding site in the Cdh23 tail 10-fold.

We found little or no role for the Cdh23 C-terminal PBM in binding harmonin. This was the case with and without the exon 68 peptide, in both CL4 cells and the in vitro binding assay. This also contradicts the prevailing model, in which the harmonin PDZ2 domain binds the Cdh23 C-terminal PBM (Böeda et al., 2002; Siemens et al., 2002; Müller, 2008; Grillet et al., 2009; Pan et al., 2009). It is difficult to envision how a competing protein or process could similarly disable the Cdh23 C-terminal PBM in two expression systems as diverse as CL4 epithelial cells and E. coli BL21 cells. Previous studies, which reached different conclusions, also used GST-Cdh23 tail constructs expressed in E. coli (Böeda et al., 2002; Siemens et al., 2002). Our GST-Cdh23 tail $\Delta$ C4 constructs showed the expected slight reduction in apparent molecular mass, and we saw no significant decrease in harmonin binding after deleting as many as 108 residues from the Cdh23 cytoplasmic tail. To our knowledge, the harmonin PDZ2 domain has been shown to bind to the Cdh23 C-terminal PBM in vitro only when examined in isolation (Böeda et al., 2002; Siemens et al., 2002; Grillet et al., 2009; Pan et al., 2009) or when joined with the PDZ1 domain but not the $\mathrm{N}$ domain (Böeda et al., 2002).

On the basis of our findings, we propose an alternative model for the interaction between Cdh23 and intact harmonins, one in which the dominant binding is between the harmonin $\mathrm{N}$ domain and the P3177-K3211 internal peptide in the Cdh23 cytoplasmic tail (Fig. $1 B, C$ ). Interaction between the PDZ2 domain of intact harmonin and the Cdh23 C-terminal PBM is evidently minimized as a result of spatial or conformational constraints but could conceivably become significant when the primary interaction is blocked or in response to some regulatory change. Thus, we propose that the baseline interaction between $\mathrm{Cdh} 23$ and harmonin may not be multivalent after all. Note that this model frees all three of the harmonin PDZ domains and the Cdh23 C-terminal PBM to interact with other ligands in the Usher interactome (El-Amraoui and Petit, 2005; Reiners et al., 2006; Müller, 2008) and beyond (Xu et al., 2008). Finally, note that our model is not inconsistent with the recent demonstration that a knock-in mouse containing a GLG-to-AAA missense mutation in the harmonin PDZ2 domain fails to target harmonin to upper tip-link plaques (Grillet et al., 2009). In the framework of our model, we propose that it is proteins other than Cdh23 that perform this harmonin targeting/retention role by engaging the PDZ2 domain of intact harmonin.

The combination of CL4 cells and espins creates a form of surrogate hair cell adorned by stereocilium-length parallel actinbundle-containing microvilli. We demonstrated that this system can be used to reconstitute selected aspects of stereocilium structure and function and to examine structure-activity relationships for human deafness mutations, which are difficult to investigate in situ. Consistent with the requirement for the F-actin binding sites of the espin C-terminal actin-bundling module to drive microvillar parallel actin bundle elongation (Loomis et al., 2003), the DFNB36 espin mutations c.2469delGTCA (p.Q823fsX845) 
and c.1988delAGAG (p.G662fsX664), which are associated with recessive deafness and vestibular dysfunction in humans (Naz et al., 2004), gave rise to reproducible defects in microvillar targeting and elongation. In addition, espin mRNA bearing the 1988delAGAG mutation may be subject to nonsense-mediated decay (Isken and Maquat, 2007). Together with the effects of espin deficiency as revealed in the jerker mouse (L. Zheng et al., 2000) and the positive correlations between espin levels and microvillus or stereocilium length (Loomis et al., 2003; Sekerková et al., 2006), we predict that patients homozygous for either mutation have abnormally short hair cell stereocilia.

The ability of myosin XVa to deliver specific cargo as it moves from base to tip along the parallel actin bundle at the core of the stereocilium is believed to be the basis for its requirement in stereocilium elongation (Belyantseva et al., 2005; Delprat et al., 2005). We found the espin-elongated microvilli of CL4 cells to be an advantageous in vivo actin bundle substrate for studying the motor activity of myosin XVa and for screening the effects of deafness mutations. Two of the three myosin XVa mutations we examined, corresponding to c.4351G $>$ A (p.D1451N) and c.4669A $>\mathrm{G}$ (p.K1557E), blocked accumulation at microvillar tips, consistent with inactivation of the motor domain, an outcome that would be expected to result in abnormally short stereocilia and deafness (Belyantseva et al., 2003, 2005; Delprat et al., 2005). A third mutation, corresponding to c.5117-5118GC $>$ TT (p.G1706V), showed no obvious difference from wild-type GFPmyosin $\mathrm{XVa}$ in the assay, suggesting that it does not cause marked motor inactivation. It is possible that this mutation impacts myosin $\mathrm{XVa}$ in a more subtle or different way not revealed by our standard assay. The highly conserved residues we examined are also identical in the extensively studied Dictyostelium discoideum myosin II (GenBank accession number XP_637740). Therefore, we sought additional insight into their possible roles from their positions in available crystal structures and computer simulations of mechanochemical coupling. In Dictyostelium myosin II, D1451, K1557, and G1706 are equivalent to D320, K423, and G575, respectively. These three residues are neither present within suspected actin-binding interfaces nor contained within elements believed to be directly involved in the recovery stroke mechanism (converter domain, lever-arm helix, SH1 helix, SH2 helix, relay helix, relay loop, wedge loop, switch 2 loop, or P loop) (Koppole et al., 2007). To our knowledge, D320 and G575 of Dictyostelium myosin II have not been implicated in computational studies, but K423 has been grouped among potential bending or hinge residues, depending on computational method (Yu et al., 2007). Although such highly conserved myosin motor domain residues have long been suspected to be important (Cope et al., 1996), our studies are the first to indicate major functional motor deficits for the myosin XVA D1451N and K1557E deafness mutations. The espin-elongated microvilli of CL4 cells show promise for examining the activities and mutations of the other unconventional myosin motors of hair cells, as well as motor cargoes. Finally, the CL4 cell model can readily be extended to the study of other hair cell proteins and to the proteins of other sensory cells, many of which contain espins in their microvillus-based sensory processes (Sekerková et al., 2004).

\section{References}

Amsler K, Cook JS (1985) Linear relationship of phlorizin-binding capacity and hexose uptake during differentiation in a clone of LLC-PK1 cells. J Cell Physiol 122:254-258.

Anwar S, Riazuddin S, Ahmed ZM, Tasneem S, Ateeq-ul-Jaleel, Khan SY,
Griffith AJ, Friedman TB, Riazuddin S (2009) SLC26A4 mutation spectrum associated with DFNB4 deafness and Pendred's syndrome in Pakistanis. J Hum Genet 54:266-270.

Bartles JR, Zheng L, Li A, Wierda A, Chen B (1998) Small espin: a third actin-bundling protein and potential forked protein ortholog in brush border microvilli. J Cell Biol 143:107-119.

Belyantseva IA, Adler HJ, Curi R, Frolenkov GI, Kachar B (2000) Expression and localization of prestin and the sugar transporter GLUT-5 during development of electromotility in cochlear outer hair cells. J Neurosci 20:RC116(1-5).

Belyantseva IA, Boger ET, Friedman TB (2003) Myosin XVa localizes to the tips of inner ear sensory cell stereocilia and is essential for staircase formation of the hair bundle. Proc Natl Acad Sci U S A 100:13958-13963.

Belyantseva IA, Boger ET, Naz S, Frolenkov GI, Sellers JR, Ahmed ZM, Griffith AJ, Friedman TB (2005) Myosin-XVa is required for tip localization of whirlin and differential elongation of hair-cell stereocilia. Nat Cell Biol 7:148-156.

Bitner-Glindzicz M, Lindley KJ, Rutland P, Blaydon D, Smith VV, Milla PJ, Hussain K, Furth-Lavi J, Cosgrove KE, Shepherd RM, Barnes PD, O’Brien RE, Farndon PA, Sowden J, Liu XZ, Scanlan MJ, Malcolm S, Dunne MJ, Aynsley-Green A, Glaser B (2000) A recessive contiguous gene deletion causing infantile hyperinsulinism, enteropathy and deafness identifies the Usher type 1C gene. Nat Genet 26:56-60.

Boëda B, El-Amraoui A, Bahloul A, Goodyear R, Daviet L, Blanchard S, Perfettini I, Fath KR, Shorte S, Reiners J, Houdusse A, Legrain P, Wolfrum U, Richardson G, Petit C (2002) Myosin VIIa, harmonin and cadherin 23 , three Usher I gene products that cooperate to shape the sensory hair cell bundle. EMBO J 21:6689-6699.

Bork JM, Peters LM, Riazuddin S, Bernstein SL, Ahmed ZM, Ness SL, Polomeno R, Ramesh A, Schloss M, Srisailpathy CR, Wayne S, Bellman S, Desmukh D, Ahmed Z, Khan SN, Kaloustian VM, Li XC, Lalwani A, Riazuddin S, BitnerGlindzicz M, Nance WE, Liu XZ, Wistow G, Smith RJ, Griffith AJ, Wilcox ER, Friedman TB, Morell RJ (2001) Usher syndrome 1D and nonsyndromic autosomal recessive deafness DFNB12 are caused by allelic mutations of the novel cadherin-like gene CDH23. Am J Hum Genet 68:26-37.

Carmosino M, Valenti G, Caplan M, Svelto M (2010) Polarized traffic towards the cell surface: how to find the route. Biol Cell 102:75-91.

Chen B, Li A, Wang D, Wang M, Zheng L, Bartles JR (1999) Espin contains an additional actin-binding site in its $\mathrm{N}$ terminus and is a major actinbundling protein of the Sertoli cell-spermatid ectoplasmic specialization junctional plaque. Mol Biol Cell 10:4327-4339.

Cope MJ, Whisstock J, Rayment I, Kendrick-Jones J (1996) Conservation within the myosin motor domain: implications for structure and function. Structure 4:969-987.

Dallos P, Wu X, Cheatham MA, Gao J, Zheng J, Anderson CT, Jia S, Wang X, Cheng WH, Sengupta S, He DZ, Zuo J (2008) Prestin-based outer hair cell motility is necessary for mammalian cochlear amplification. Neuron 58:333-339.

Deák L, Zheng J, Orem A, Du GG, Aguiñaga S, Matsuda K, Dallos P (2005) Effects of cyclic nucleotides on the function of prestin. J Physiol 563:483-496.

Delprat B, Michel V, Goodyear R, Yamasaki Y, Michalski N, El-Amraoui A, Perfettini I, Legrain P, Richardson G, Hardelin JP, Petit C (2005) Myo$\sin \mathrm{XVa}$ and whirlin, two deafness gene products required for hair bundle growth, are located at stereocilia tips and interact directly. Hum Mol Genet 14:401-410.

Di Palma F, Holme RH, Bryda EC, Belyantseva IA, Pellegrino R, Kachar B, Steel KP, Noben-Trauth K (2001a) Mutations in Cdh23, encoding a new type of cadherin, cause stereocilia disorganization in waltzer, the mouse model for Usher syndrome type 1D. Nat Genet 27:103-107.

Di Palma F, Pellegrino R, Noben-Trauth K (2001b) Genomic structure, alternative splice forms and normal and mutant alleles of cadherin 23 (Cdh23). Gene 281:31-41.

Donaudy F, Zheng L, Ficarella R, Ballana E, Carella M, Melchionda S, Estivill $\mathrm{X}$, Bartles JR, Gasparini P (2006) Espin gene (ESPN) mutations associated with autosomal dominant hearing loss cause defects in microvillar elongation or organisation. J Med Genet 43:157-161.

Doyle DA, Lee A, Lewis J, Kim E, Sheng M, MacKinnon R (1996) Crystal structures of a complexed and peptide-free membrane protein-binding domain: molecular basis of peptide recognition by PDZ. Cell 85:1067-1076.

El-Amraoui A, Petit C (2005) Usher I syndrome: unravelling the mecha- 
nisms that underlie the cohesion of the growing hair bundle in inner ear sensory cells. J Cell Sci 118:4593-4603.

Everett LA, Glaser B, Beck JC, Idol JR, Buchs A, Heyman M, Adawi F, Hazani E, Nassir E, Baxevanis AD, Sheffield VC, Green ED (1997) Pendred syndrome is caused by mutations in the putative sulphate transporter gene (PDS). Nat Genet 17:411-422.

Fölsch H (2005) The building blocks for basolateral vesicles in polarized epithelial cells. Trends Cell Biol 15:222-228.

Fölsch H, Ohno H, Bonifacino JS, Mellman I (1999) A novel clathrin adaptor complex mediates basolateral targeting in polarized epithelial cells. Cell 99:189-198.

Furness DN, Mahendrasingam S, Ohashi M, Fettiplace R, Hackney CM (2008) The dimensions and composition of stereociliary rootlets in mammalian cochlear hair cells: comparison between high- and lowfrequency cells and evidence for a connection to the lateral membrane. J Neurosci 28:6342-6353.

Geeves MA, Holmes KC (1999) Structural mechanism of muscle contraction. Annu Rev Biochem 68:687-728.

Grati M, Aggarwal N, Strehler EE, Wenthold RJ (2006) Molecular determinants for differential membrane trafficking of PMCA1 and PMCA2 in mammalian hair cells. J Cell Sci 119:2995-3007.

Grillet N, Xiong W, Reynolds A, Kazmierczak P, Sato T, Lillo C, Dumont RA, Hintermann E, Sczaniecka A, Schwander M, Williams D, Kachar B, Gillespie PG, Müller U (2009) Harmonin mutations cause mechanotransduction defects in cochlear hair cells. Neuron 62:375-387.

Harris BZ, Lim WA (2001) Mechanism and role of PDZ domains in signaling complex assembly. J Cell Sci 114:3219-3231.

Isken O, Maquat LE (2007) Quality control of eukaryotic mRNA: safeguarding cells from abnormal mRNA function. Genes Dev 21:1833-1856.

Jensen-Smith H, Hallworth R (2007) Lateral wall protein content mediates alterations in cochlear outer hair cell mechanics before and after hearing onset. Cell Motil Cytoskeleton 64:705-717.

Kaltenbach JA, Falzarano PR, Simpson TH (1994) Postnatal development of the hamster cochlea. II. Growth and differentiation of stereocilia bundles. J Comp Neurol 350:187-198.

Kazmierczak P, Sakaguchi H, Tokita J, Wilson-Kubalek EM, Milligan RA, Müller U, Kachar B (2007) Cadherin 23 and protocadherin 15 interact to form tip-link filaments in sensory hair cells. Nature 449:87-91.

Kim YH, Kwon TH, Frische S, Kim J, Tisher CC, Madsen KM, Nielsen S (2002) Immunocytochemical localization of pendrin in intercalated cell subtypes in rat and mouse kidney. Am J Physiol Renal Physiol 283:F744-F754.

Kopp P, Pesce L, Solis-S JC (2008) Pendred syndrome and iodide transport in the thyroid. Trends Endocrinol Metab 19:260-268.

Koppole S, Smith JC, Fischer S (2007) The structural coupling between ATPase activation and recovery stroke in the myosin II motor. Structure 15:825-837.

Lagziel A, Ahmed ZM, Schultz JM, Morell RJ, Belyantseva IA, Friedman TB (2005) Spatiotemporal pattern and isoforms of cadherin 23 in wild type and waltzer mice during inner ear hair cell development. Dev Biol 280:295-306.

Lagziel A, Overlack N, Bernstein SL, Morell RJ, Wolfrum U, Friedman TB (2009) Expression of cadherin 23 isoforms is not conserved: implications for a mouse model of Usher syndrome type 1D. Mol Vis 15:1843-1857.

Lefèvre G, Michel V, Weil D, Lepelletier L, Bizard E, Wolfrum U, Hardelin JP, Petit C (2008) A core cochlear phenotype in USH1 mouse mutants implicates fibrous links of the hair bundle in its cohesion, orientation and differential growth. Development 135:1427-1437.

Li A, Xue J, Peterson EH (2008) Architecture of the mouse utricle: macular organization and hair bundle heights. J Neurophysiol 99:718-733.

Loomis PA, Zheng L, Sekerková G, Changyaleket B, Mugnaini E, Bartles JR (2003) Espin cross-links cause the elongation of microvillus-type parallel actin bundles in vivo. J Cell Biol 163:1045-1055.

Loomis PA, Kelly AE, Zheng L, Changyaleket B, Sekerková G, Mugnaini E, Ferreira A, Mullins RD, Bartles JR (2006) Targeted wild-type and jerker espins reveal a novel, WH2 domain-dependent way to make actin bundles in cells. J Cell Sci 119:1655-1665.

Mburu P, Mustapha M, Varela A, Weil D, El-Amraoui A, Holme RH, Rump A, Hardisty RE, Blanchard S, Coimbra RS, Perfettini I, Parkinson N, Mallon AM, Glenister P, Rogers MJ, Paige AJ, Moir L, Clay J, Rosenthal A, Liu XZ, Blanco G, Steel KP, Petit C, Brown SD (2003) Defects in whirlin, a PDZ domain molecule involved in stereocilia elongation, cause deafness in the whirler mouse and families with DFNB31. Nat Genet 34:421-428.

McEwen DP, Schumacher SM, Li Q, Benson MD, Iñiguez-Lluhí JA, Van Genderen KM, Martens JR (2007) Rab-GTPase-dependent endocytic recycling of Kv1.5 in atrial myocytes. J Biol Chem 282:29612-29620.

Michalski N, Michel V, Caberlotto E, Lefèvre GM, van Aken AF, Tinevez JY, Bizard E, Houbron C, Weil D, Hardelin JP, Richardson GP, Kros CJ, Martin P, Petit C (2009) Harmonin b, an actin-binding scaffold protein, is involved in the adaptation of mechanoelectrical transduction by sensory hair cells. Pflugers Arch 459:115-130.

Michel V, Goodyear RJ, Weil D, Marcotti W, Perfettini I, Wolfrum U, Kros CJ, Richardson GP, Petit C (2005) Cadherin 23 is a component of the transient lateral links in the developing hair bundles of cochlear sensory cells. Dev Biol 280:281-294.

Mount DB, Romero MF (2004) The SLC26 gene family of multifunctional anion exchangers. Pflugers Arch 447:710-721.

Müller U (2008) Cadherins and mechanotransduction by hair cells. Curr Opin Cell Biol 20:557-566.

Nagata K, Zheng L, Madathany T, Castiglioni AJ, Bartles JR, García-Añoveros J (2008) The varitint-waddler (Va) deafness mutation in TRPML3 generates constitutive, inward rectifying currents and causes cell degeneration. Proc Natl Acad Sci U S A 105:353-358.

Nal N, Ahmed ZM, Erkal E, Alper OM, Lüleci G, Dinç O, Waryah AM, Ain Q, Tasneem S, Husnain T, Chattaraj P, Riazuddin S, Boger E, Ghosh M, Kabra M, Riazuddin S, Morell RJ, Friedman TB (2007) Mutational spectrum of MYO15A: The large N-terminal extension of myosin XVa is required for hearing. Hum Mutat 28:1014-1019.

Navaratnam D, Bai JP, Samaranayake H, Santos-Sacchi J (2005) N-terminalmediated homomultimerization of prestin, the outer hair cell motor protein. Biophys J 89:3345-3352.

Naz S, Griffith AJ, Riazuddin S, Hampton LL, Battey JF Jr, Khan SN, Riazuddin S, Wilcox ER, Friedman TB (2004) Mutations of ESPN cause autosomal recessive deafness and vestibular dysfunction. J Med Genet 41:591-595.

Pan L, Yan J, Wu L, Zhang M (2009) Assembling stable hair cell tip link complex via multidentate interactions between harmonin and cadherin 23. Proc Natl Acad Sci U S A 106:5575-5580.

Peng AW, Belyantseva IA, Hsu PD, Friedman TB, Heller S (2009) Twinfilin 2 regulates actin filament lengths in cochlear stereocilia. J Neurosci 29:15083-15088.

Purdy KR, Bartles JR, Wong GC (2007) Structural polymorphism of the actin-espin system: a prototypical system of filaments and linkers in stereocilia. Phys Rev Lett 98:058105.

Rayment I, Holden HM, Sellers JR, Fananapazir L, Epstein ND (1995) Structural interpretation of the mutations in the $\beta$-cardiac myosin that have been implicated in familial hypertrophic cardiomyopathy. Proc Natl Acad Sci U S A 92:3864-3868.

Reiners J, Nagel-Wolfrum K, Jürgens K, Märker T, Wolfrum U (2006) Molecular basis of human Usher syndrome: deciphering the meshes of the Usher protein network provides insights into the pathomechanisms of the Usher disease. Exp Eye Res 83:97-119.

Royaux IE, Suzuki K, Mori A, Katoh R, Everett LA, Kohn LD, Green ED (2000) Pendrin, the protein encoded by the Pendred syndrome gene (PDS), is an apical porter of iodide in the thyroid and is regulated by thyroglobulin in FRTL-5 cells. Endocrinology 141:839-845.

Royaux IE, Belyantseva IA, Wu T, Kachar B, Everett LA, Marcus DC, Green ED (2003) Localization and functional studies of pendrin the mouse inner ear provide insight about the etiology of deafness in pendred syndrome. J Assoc Res Otolaryngol 4:394-404.

Sekerková G, Zheng L, Loomis PA, Changyaleket B, Whitlon DS, Mugnaini E, Bartles JR (2004) Espins are multifunctional actin cytoskeletal regulatory proteins in the microvilli of chemosensory and mechanosensory cells. J Neurosci 24:5445-5456.

Sekerková G, Zheng L, Mugnaini E, Bartles JR (2006) Differential expression of espin isoforms during epithelial morphogenesis, stereociliogenesis and postnatal maturation in the developing inner ear. Dev Biol 291:83-95.

Shcheynikov N, Yang D, Wang Y, Zeng W, Karniski LP, So I, Wall SM, Muallem S (2008) The Slc26a4 transporter functions as an electroneutral $\mathrm{Cl}^{-} / \mathrm{I}^{-} / \mathrm{HCO}_{3}^{-}$exchanger: role of Slc26a4 and Slc26a6 in $\mathrm{I}^{-}$and $\mathrm{HCO}_{3-}$ secretion and in regulation of CFTR in the parotid duct. J Physiol 586:3813-3824.

Shin H, Purdy Drew KR, Bartles JR, Wong GC, Grason GM (2009) Coop- 
erativity and frustration in protein-mediated parallel actin bundles. Phys Rev Lett 103:238102.

Siemens J, Kazmierczak P, Reynolds A, Sticker M, Littlewood-Evans A, Müller U (2002) The Usher syndrome proteins cadherin 23 and harmonin form a complex by means of PDZ-domain interactions. Proc Natl Acad Sci U S A 99:14946-14951.

Siemens J, Lillo C, Dumont RA, Reynolds A, Williams DS, Gillespie PG, Müller U (2004) Cadherin 23 is a component of the tip link in hair-cell stereocilia. Nature 428:950-955.

Soni LE, Warren CM, Bucci C, Orten DJ, Hasson T (2005) The unconventional myosin-VIIa associates with lysosomes. Cell Motil Cytoskeleton 62:13-26.

Stauffer TP, Ahn S, Meyer T (1998) Receptor-induced transient reduction in plasma membrane PtdIns $(4,5) \mathrm{P}_{2}$ concentration monitored in living cells. Curr Biol 8:343-346.

Tilney LG, Tilney MS, Saunders JS, DeRosier DJ (1986) Actin filaments, stereocilia, and hair cells of the bird cochlea. III. The development and differentiation of hair cells and stereocilia. Dev Biol 116:100-118.

Tyska MJ, Mooseker MS (2002) MYO1A (brush border myosin I) dynamics in the brush border of LLC-PK1-CL4 cells. Biophys J 82:1869-1883.

Verpy E, Leibovici M, Zwaenepoel I, Liu XZ, Gal A, Salem N, Mansour A, Blanchard S, Kobayashi I, Keats BJ, Slim R, Petit C (2000) A defect in harmonin, a PDZ domain-containing protein expressed in the inner ear sensory hair cells, underlies Usher syndrome type 1C. Nat Genet 26:51-55.

Vollrath MA, Kwan KY, Corey DP (2007) The micromachinery of mechanotransduction in hair cells. Annu Rev Neurosci 30:339-365.

Whitlon DS, Ketels KV, Coulson MT, Williams T, Grover M, Edpao W,
Richter CP (2006) Survival and morphology of auditory neurons in dissociated cultures of newborn mouse spiral ganglion. Neuroscience 138:653-662.

Xu Z, Peng AW, Oshima K, Heller S (2008) MAGI-1, a candidate stereociliary scaffolding protein, associates with the tip-link component cadherin 23. J Neurosci 28:11269-11276.

Yengo CM, Ananthanarayanan SK, Brosey CA, Mao S, Tyska MJ (2008) Human deafness mutation E385D disrupts the mechanochemical coupling and subcellular targeting of myosin-1a. Biophys J 94:L5-L7.

Yu H, Ma L, Yang Y, Cui Q (2007) Mechanochemical coupling in the myosin motor domain. II. Analysis of critical residues. PLoS Comput Biol 3:e23.

Yu N, Zhu ML, Zhao HB (2006) Prestin is expressed on the whole outer hair cell basolateral surface. Brain Res 1095:51-58.

Zheng J, Shen W, He DZ, Long KB, Madison LD, Dallos P (2000) Prestin is the motor protein of cochlear outer hair cells. Nature 405:149-155.

Zheng J, Long KB, Matsuda KB, Madison LD, Ryan AD, Dallos PD (2003) Genomic characterization and expression of mouse prestin, the motor protein of outer hair cells. Mamm Genome 14:87-96.

Zheng J, Du GG, Matsuda K, Orem A, Aguiñaga S, Deák L, Navarrete E, Madison LD, Dallos P (2005) The C-terminus of prestin influences nonlinear capacitance and plasma membrane targeting. J Cell Sci 118:29872996.

Zheng L, Sekerková G, Vranich K, Tilney LG, Mugnaini E, Bartles JR (2000) The deaf jerker mouse has a mutation in the gene encoding the espin actin-bundling proteins of hair cell stereocilia and lacks espins. Cell 102: 377-385. 